\title{
Novel inhibitors of Eukaryotic Elongation Factor 2 Kinase: In silico, synthesis, and in vitro studies
}

\author{
Ferah Comert Onder ${ }^{1-3}$, Serdar Durdagi ${ }^{4}$, Nermin Kahraman ${ }^{2}$, Tugce Nur Uslu ${ }^{5}$, Hakan \\ Kandemir $^{5}$, Esen Bellur Atici ${ }^{6}$, Bulent Ozpolat ${ }^{2,7, *}$, Mehmet Ay, ${ }^{1, *}$
}

${ }^{1}$ Department of Medical Biology, Faculty of Medicine, Çanakkale Onsekiz Mart University, 17020 Canakkale, Turkey

${ }^{2}$ Department of Experimental Therapeutics, The University of Texas MD Anderson Cancer Center, Houston, Texas 77030, United States

${ }^{3}$ Department of Chemistry, Faculty of Science and Arts, Natural Products and Drug Research Laboratory, Çanakkale Onsekiz Mart University, 17020 Canakkale, Turkey

${ }^{4}$ Computational Biology and Molecular Simulations Laboratory, Department of Biophysics, School of Medicine Bahcesehir University, 34734 İstanbul, Turkey

${ }^{5}$ Department of Chemistry, Tekirdağ Namık Kemal University, Tekirdağ, Turkey

${ }^{6}$ DEVA Holding A.S. Cerkezkoy, Tekirdag, Turkey

${ }^{7}$ Department of Experimental Therapeutics and Center for RNA Interference and Non-Coding RNAs, The University of Texas MD Anderson Cancer Center, Houston, Texas 77030, United States

Correspondence: Mehmet Ay, PhD, Department of Chemistry, Faculty of Science and Arts, 17020 Canakkale, Turkey Email: mehmetay06@comu.edu.tr Bulent Ozpolat MD, PhD, Department of Experimental Therapeutics, The University of Texas MD Anderson Cancer Center, 1515 Holcombe Boulevard, Houston, TX 77030, USA Email: bozpolat@mdanderson.org

\# Patent pending (WO2019240701) 


\section{ABSTRACT}

Eukaryotic elongation factor 2 kinase $(\mathrm{eEF} 2 \mathrm{~K})$ is an unusual alpha kinase whose expression is highly upregulated in various cancers and contributes to tumor growth, metastasis, and progression. More importantly, expression of eEF2K is associated with poor clinical outcome and shorter patient survival triple negative breast cancer (TNBC). Therefore, eEF2K is an emerging molecular target for development of novel targeted therapeutics and precision medicine in solid cancers. However, currently potent, and specific inhibitors of eEF2K are not available for clinical translation. In the current study, we investigated the effects of various newly designed and synthesized a series of compounds with coumarin scaffold substitutions in inhibiting eEF2K activity using in silico approaches and in vitro studies in TNBC cells. We utilized an amide substitution at 3-position on the coumarin ring with their pharmacologically active groups containing pyrrolidine, piperidine, morpholine and piperazine groups with $-\left(\mathrm{CH}_{2}\right)_{2}-$ bridged for aliphatic amides. To evaluate substituent effects on coumarin scaffold, boronic acid pinacol ester and boronic acids on phenyl rings were investigated using in silico and in vitro analyses. Due to their ability to form covalent binding to the target enzyme, we investigated the effects of boron containing groups on functionalized coumarin ring ( 3 compounds) and designed novel aliphatic and aromatic derivatives of coumarin scaffolds (10 compounds) and phenyl ring with boron groups (4 compounds). In silico analysis and molecular docking studies were performed using the Glide/SP module of Maestro molecular modeling package. According to obtained results, structure activity relationship (SAR) was carried out. Among the newly designed, synthesized, and tested compounds, our in vitro findings revealed that several compounds displayed a highly effective eEF2K inhibition at submicromolar concentration in in vitro breast cancer cells. In conclusion, we identified novel eEF2K inhibitors as promising anticancer drug substance candidates which should be further evaluated by in vivo studies, preclinical and clinical studies.

KEYWORDS. Coumarin, benzopyran, $2 \mathrm{H}$-chromene, coumarin carboxamide, EF2K, eEF2K, eEF-2K, molecular docking, molecular dynamics, drug design, development, cancer, breast cancer, targeted therapy 


\section{INTRODUCTION}

Heterocyclic compounds are fundamental structures in organic chemistry ${ }^{1,2}$ and possess a ring structure that contains various heteroatoms such as $\mathrm{N}, \mathrm{O}$ or $\mathrm{S}$ in their aromatic and nonaromatic rings. ${ }^{3}$ They are often used in the fields of organic synthesis and pharmaceutical industry for the development of drugs. ${ }^{1,4}$ Coumarins (1,2-benzopyrone; $2 \mathrm{H}$-1-benzopyran-2-one, chromene) are oxygenated heterocycles, because of their effective nucleus structure, they are widely known for their various pharmacologically relevant features such as anti-inflammatory ${ }^{5}$, antibacterial ${ }^{6}$, antimutagenic ${ }^{7}$, and anticancer activities. ${ }^{8-10}$ The effects of coumarins have been shown as inhibitors of several kinase pathways, cell cycle distribution, apoptosis, heat shock protein (HSP90) and carbonic anhydrase. ${ }^{11-13}$ For instance, warfarin, dicoumarol, acenocoumarol and phenprocoumon (anticoagulants), novobiocin and clorobiocin (antibiotics) and calanolide A (antiviral) have been used as drugs, indicating that coumarin compounds have a broad-spectrum of use in various pharmaceuticals. ${ }^{14-16}$ Therefore, recently interest in these compounds has significantly increased for the discovery of structural substitution to enhance activities of these compounds. ${ }^{13,17,18}$ This circumstance led to improve the studies of structure-activity relationships (SAR) for further drug discovery program.

Protein kinase catalyzes the transfer phosphate group to their target substrate protein and are critical for signaling pathways. Eukaryotic elongation factor 2 kinase $(e E F 2 K)$ is an unusual alpha kinase and regulated by calcium calmodulin. ${ }^{19} \mathrm{eEF} 2 \mathrm{~K}$ is involved in the regulation of the global protein synthesis of protein synthesis, by controlling the peptide chain elongation phase by phosphorylation of its substrate Elongation factor 2 (EF2). eEF2K expression is highly upregulated in cancer cells such as breast, pancreatic, and lung tumors and its expression is associated with poor clinical outcome and shorter patient survival. ${ }^{20-22}$ In our previous reports, we demonstrated the role of eEF2K as molecular driver of breast, pancreatic and lung cancer cell proliferation, motility, invasion, drug resistance, tumor growth and progression and validated it as a potential molecular target using RNAi based therapeutics. ${ }^{20,22-26}$ Because of its clinical significance and critical role in tumor growth and progression, $\mathrm{eEF} 2 \mathrm{~K}$ is an emerging molecular target for the development of targeted therapeutics and precision medicine and has been the center of efforts to discover of new therapeutics specifically targeting its activity in cancer. Furthermore, although there are several eEF2K inhibitors have been reported, none of them is potent and specific for eEF2K inhibition and translation into clinical trials. ${ }^{19,27,28}$ We have previously identified highly 
effective coumarin-based eEF2K inhibitors. ${ }^{17}$ Therefore, in the current study, we investigated the effects of various substituted coumarin scaffolds in inhibiting eEF2K activity using in silico approaches and in vitro studies. We designed and synthesized a series of novel compounds including coumarin-based structures, ${ }^{29} 2 \mathrm{H}$-chromen-3-carboxamide (coumarin-3-carboxamide) derivatives at 3-position on coumarin ring with the pharmacologically active groups containing pyrrolidine, piperidine, morpholine and piperazine groups with $-\left(\mathrm{CH}_{2}\right)_{2}$ - bridges for aliphatic amides. To evaluate substituent effects on the target kinase inhibition coumarin ring, boronic acid pinacol ester and phenyl boronic acids were investigated by in silico and in vitro analysis.

Because the boron functional group is able to form covalent binding with target enzymes, ${ }^{30,31}$ we evaluated the effects of several boron containing compounds and in terms of their function as eEF2K inhibitors and their therapeutic properties. As reported in published studies, ${ }^{32,33}$ boron containing compounds have been shown to exert inhibitory effects at low concentrations. Therefore, we also investigated the effects of boron groups on functionalized aromatic rings on coumarin scaffold. We designed novel substituted coumarin compounds containing boronic acid ester and boronic acids (compounds 11-13) and various aromatic amides with substituted boronic acid groups (compounds 14-17) as well as aliphatic and aromatic amide derivatives of coumarin scaffolds (compounds 1-10) via in silico approaches and investigated their ability for inhibiting eEF2K in breast cancer cells. Molecular docking study was performed for all the synthesized compounds. Among these compounds, in vitro test results revealed that synthesized compounds $(\mathbf{1}, \mathbf{3}, \mathbf{4}, \mathbf{6}, \mathbf{7}, \mathbf{1 1})$ displaying eEF2K inhibition at low concentrations ranging between $0.1,0.5$ and $1 \mu \mathrm{M}$ in breast cancer cells. Throughout computational and inhibition studies, SAR of the compounds were evaluated in detail.

Our combined studies led to the design of novel and highly effective eEF2K inhibitors for development of newly therapeutics. The effect of these novel eEF2K inhibitors as promising candidates may provide effective and potent in vivo targeting of oncogenic eEF2K signaling in breast and other cancer types and present promising candidates for preclinical development and clinically applicable therapeutics. 


\section{RESULTS AND DISCUSSION}

Molecular Modeling Studies. Seventeen synthesized compounds (1-17) were prepared at a neutral $\mathrm{pH}$ and energy optimizations were performed by using AM1 and PM3 semi-empirical approaches with semiempirical NDDO modules of the Maestro. Geometrically optimized compounds and obtained partial charges were used in docking simulations. The model structure of the eEF2K protein that was reported by us previously was used as target structure. ${ }^{17}$ The protein structure was prepared at physiological $\mathrm{pH}$ and protonation states of each residue was identified by PROPKA. ${ }^{34,35}$ The Glide/SP module of the Maestro molecular modeling package was used in docking. ${ }^{36}$ As shown in Table 1, the results of docking scores show that aliphatic amide substituted coumarin compounds 4-6 have the highest docking scores $(-7.334,-7.208$, and $-7.014 \mathrm{kcal} / \mathrm{mol}$, respectively) at the binding site of the eEF2K. Among the boron containing compounds (11-13 and 14-17), aromatic amide substituted coumarin compound (11) had the highest docking score ($6.121 \mathrm{kcal} / \mathrm{mol})$. Furthermore, molecular docking scores of previously published eEF2K inhibitor compounds such as A484954 (-5.621 kcal/mol), NH125 (-4.503 kcal/mol), TX-1918 (-5.533 $\mathrm{kcal} / \mathrm{mol}$ ) had much lower scores, except nonspecific eEF-2K inhibitor Rottlerin (-8.263, $\mathrm{kcal} / \mathrm{mol}$ ), suggesting that our lead compounds ${ }^{29}$ are superior compared to the previously published inhibitors. ${ }^{19,27,28}$

\section{Table 1}

Chemistry. The newly synthesized compounds (1-17) were prepared by known methods ${ }^{38,39}$ with small modifications as shown in Figures 1 and 2. Knoevenagel condensation reaction was carried out for the synthesis of starting compounds (a-d) with commercially available chemicals. Compounds (1-7) in Figure 1 were produced via ester-amide exchange reaction by ethoxy carbonyl coumarins and aliphatic amines including 2-(pyrrolidin-1-yl)ethane-1-amine, 2(piperidine-1-yl)ethane-1-amine, 2-morpholinoethane-1-amine and 2-(piperazin-1-yl)ethan-1amine in ethanol (EtOH) at reflux temperature with changing yields from $41 \%$ and $83 \%$. Purification of compounds was achieved by silica-gel column chromatography and/or treating them with various solvents. As shown in Figure 2, compound $\mathbf{8}$ was synthesized as a tertiary amide 
using a coupling reagent, EDCI ( $N$-(3-dimethylaminopropyl)- $N$ '-ethylcarbodiimide hydrochloride), according to the previously published methodology. ${ }^{17,38}$ Subsequently, trifluoroacetic acid was used to remove the protection group to obtain compound 9. Moreover, the common amidation reaction was utilized by using coupling reagent, tripropylphosphonic anhydride (T3P) in 50\% ethyl acetate solution for the synthesis of compounds $\mathbf{1 0}$ and 11-13. ${ }^{39}$ The reaction mixture was stirred at room temperature for $24 \mathrm{~h}$ following the addition of related aromatic amines containing 5-amino-2-chloro-benzotrifluoride (for 10) and 4-aminophenylboronic acid pinacol ester (for 11-13).

\section{Figure 1}

\section{Figure 2}

Boron functional group has been utilized for designing of novel therapeutics including bortezomib that was approved by the FDA for the treatment of various hematological cancers. ${ }^{32,40}$ Several other boron-based compounds are in various phases of clinical trials, suggesting the promise of this approach for medicinal chemists. ${ }^{33}$ Therefore, in this study, novel phenylboronic acid pinacol ester compounds containing coumarin scaffold $(\mathbf{1 1}, \mathbf{1 2})$ and various aromatic amides with substituted groups (14-16) were successfully synthesized. Commercially available substituted phenylboronic acid pinacol ester and synthesized starting material, 6-methoxy-3-carboxycoumarin (d) were treated in various solvents such as dimethylformamide (DMF) and tetrahydrofuran (THF) at room temperature. Boronic acid pinacol ester derived compound $\mathbf{1 4}$ was designed using gallic acid core structure. Methylene group was specifically linked to this compound to provide enhanced flexibility. Compound $\mathbf{1 4}$ was synthesized using related boronic acid pinacol ester, EDCI and HOBt (1-Hydroxybenzotriazole hydrate) in $N, N$-dimethylformamide (DMF) at room temperature for $24 \mathrm{~h}$ with the similar method of compound $8 .^{17,29,38}$ Removing pinacol ester group was achieved with sodium periodate $\left(\mathrm{NaIO}_{4}\right)$ and $1 \mathrm{~N}$ hydrochloric acid $(\mathrm{HCl})$ in tetrahydrofuran $(\mathrm{THF})$ and water to obtain compounds 12, 13 and $17 .{ }^{41}$ In spectroscopic analyses, FTIR, ${ }^{1} \mathrm{H}$ NMR and ${ }^{13} \mathrm{C}$ NMR, we observed characteristic peaks representing all compounds. LC-MS/MS and HRMS analysis were performed. Related spectroscopic data are presented in Supporting Information (SI). 


\section{Table 2}

In vitro evaluation of eEF2K Activity. To evaluate the effects of the newly synthesized compounds on eEF2K, we used triple negative breast cancer cells, MDA-MB-231, and investigated for the ability to inhibit eEF2K. We found significant inhibition of eEF2K activity by compounds 1, 3, 4, 6, 7 and 11 at $0.1-1 \mu \mathrm{M}$ concentrations in MDA-MB-231 cells are detected by reduced Threonine-56 phosphorylation of EF-2 (p-EF2-Thr56), which is the only known downstream substrate of eEF2K (Figure 3A-C). Compound 10 inhibited eEF2K at $2.5 \mu \mathrm{M}$ while compound 14 did not show inhibition effect in MDA-MB-231 cells at tested low concentrations (Figure 3C). Because of low docking scores, some of the compounds were not selected for their in vitro biological tests (i.e., 15-17).

The eEF2K inhibitory potentials of the compounds $1,3,4,6,7$ and 11 were found to be the highest level compared to controls and other compounds in the cells. These highly effective coumarin scaffolds incorporating pyrrolidine, morpholine, piperidine and boronic acid pinacol ester groups linked with $-\left(\mathrm{CH}_{2}\right)_{2}-$ bridge (for $\left.\mathbf{1 , 3}, \mathbf{4}, \mathbf{6}, \mathbf{7}\right)$ and phenyl ring (for 11) provided better results in terms of eEF2K inhibition compared to our previously reported potential eEF2K inhibitors A1 and A2 that have coumarin scaffolds bridged to substituted phenyl ring at 3position. ${ }^{17}$ Although A1 and A2 compounds that have provided effective eEF2K inhibition at 1 and $2.5 \mu \mathrm{M}$ in breast cancer cells, compounds containing morpholine and tert-butyl piperazine-1carboxylate groups that linked with methylene bridge to phenyl ring at 3-position of coumarin scaffold led to significant change in the eEF2K inhibitory effect compared with compounds incorporating heterocyclic amines such as pyrrolidine, morpholine and piperidine groups that directly bind with ethylene bridge to form coumarin 3 carboxamides.

In addition, coumarin carboxamide derivative that is substituted with boronic acid pinacol ester on phenyl ring (11) inhibited eEF2K activity in TNBC cells at $0.1 \mu \mathrm{M}$. Following promising in silico and in vitro results with regard to eEF2K inhibition, we examined the effect of coumarin scaffold and the effects of various groups on coumarin and phenyl rings SAR studies in detail for the first time in this study. As a result, as indicated by the molecular modeling studies, the main contribution to the eEF2K inhibitor was provided by the coumarin ring in the compounds. 


\section{Figure 3}

Structure-activity relationship (SAR) study. SAR was analyzed using in silico and in vitro results (Figure 4). Compounds (1-7) were especially linked to heterocyclic amines with $-\left(\mathrm{CH}_{2}\right)_{2}-$ bridges at 3-position of coumarin scaffold. Morpholine and piperazine groups are found in the backbones of pharmacologically active compounds used in medicinal chemistry.

Coumarins, a class of heterocyclic compounds have significant activities, ${ }^{5-13,42}$ such as 2-oxo$2 \mathrm{H}$-chromene-3-carboxamides have been reported for their biological and pharmaceutical activities. ${ }^{43-46}$ As expected, coumarin compounds are highly effective at low concentrations, thus they have potential to be used for targeted therapies. ${ }^{8}$ In our studies, we found that highly effective compounds include coumarin structure. ${ }^{17,37}$ In addition, we found that the compounds with hydroxyl group $(-\mathrm{OH})$ at 6-position of coumarin ring, containing pyrrolidine (4), morpholine (6) and $N$-methyl piperazine (7), respectively, inhibited effectively eEF2K activity at $1 \mu \mathrm{M}$ in MDAMB-231 cells. Although there is a hydrogen substitution at 6-position of coumarin scaffold for compounds (2 (-6.258 kcal/mol) and $3(-6.121 \mathrm{kcal} / \mathrm{mol}))$ possessing piperidine and morpholine groups, respectively, contribute to eEF2K inhibition, our results demonstrate that the hydroxyl substitution may provide better efficacy concentrations.

In addition, molecular docking studies further demonstrated that the compounds (i.e., 4 (-7.334 $\mathrm{kcal} / \mathrm{mol}), 5(-7.208 \mathrm{kcal} / \mathrm{mol})$ and $\mathbf{6}(-7.014 \mathrm{kcal} / \mathrm{mol}))$ were highly effective with engaging with eEF2K and provided evidence supporting our in vitro results in breast cancer cells. Figure 4A-C shows that the top docking pose of compound $\mathbf{6}$ interacting with related amino acids at the binding pocket of target enzyme and hydroxyl substitution at 6-position on coumarin ring contribute to the activity. The in vitro data showed compound 7 that has a free $-\mathrm{NH}$ group on piperazine showed remarkable inhibition against eEF2K below $1 \mu \mathrm{M}$. Although compound $\mathbf{1 0}$ possesses significant trifluoromethyl group, it has not a high docking score $(-5.870 \mathrm{kcal} / \mathrm{mol})$ to eEF2K and it showed an inhibition at $2.5 \mu \mathrm{M}$ in in vitro analysis.

\section{Figure 4}


On the other hand, among the boron containing compounds, aromatic amide substituted coumarin compound containing boronic acid pinacol ester at 4-position of phenyl ring that is linked to coumarin at 3-position (11 (-6.121 kcal/mol)) showed high eEF2K inhibition at concentration as low as $0.1 \mu \mathrm{M}$ in breast cancer cells. When compared to compounds 1-7, we can indicate that the hydroxyl substitution on the coumarin ring contributes to the inhibition. The molecular docking results show that compounds 14-17 that have phenyl substitution with various groups including nitro $\left(-\mathrm{NO}_{2}\right),-\mathrm{CF}_{3}$ and boron containing groups, may not effectively bind to the active pocket of EF2K enzyme. Finally, we determined no activity at low concentrations with tertiary aliphatic amide coumarin compounds (B1-B4) that directly bind to carbonyl group with heterocyclic amines in our previously reported study. ${ }^{17}$ Herein, we determined highly effective potent eEF2K inhibitors including similar heterocyclic amines that linked to coumarin scaffold at 3-position with two methylene bridges $\left(-\mathrm{CH}_{2}-\right)_{2}$ to form secondary amide. According to our results, a proposed SAR study was shown in Figure 5.

\section{Figure 5}

This is the first study that was designed to identify highly effective and potent eEF2K inhibitor compounds. In addition, the designed and synthesized compounds (1-3) were reported in the literature $^{47-49}$ and compounds $\mathbf{2}$ and $\mathbf{3}$ were studied to be used for Alzheimer's disease. Herein, for the first time these compounds (1-3) were examined and reported as eEF2K inhibitors for the treatment of breast cancer. We believe that this study will contribute to further studies to be used in cancer therapy. Based on our previously published study, ${ }^{17}$ as expected $2 \mathrm{H}$-chromen-3carboxamide compounds provided highly effective eEF2K inhibition at submicromolar concentrations. We found that methylene bridges and boronic acid pinacol ester substitution contributed to inhibition compared to aliphatic and aromatic coumarin carboxamides, respectively. In the molecular docking studies, hydroxy substitution at 6-position of coumarin scaffold interacted with the target enzyme (Figure 4). Coumarins have been demonstrated to have anticancer features because of their pharmacological and inhibitory activity of various kinases. Anticancer activity of coumarins as different kinase inhibitors were reported in SAR studies with several pharmacophore groups including hydrazide-hydrazone backbone and bromine substitution at 6-position on coumarin ring affected positively antitumor activity because of its electronegative 
effect. ${ }^{13}$ Whereas electronegative groups in compound $\mathbf{1 0}$ did not contribute to eEF2K inhibition in our study. eEF2K inhibition activity of substituted coumarin (1-13) and benzamide (14-17) compounds provided highly effective scaffolds for eEF2K inhibition, suggesting that these compounds have potential therapeutic effect as inhibitors of eEF2K activity.

In order to better understand the ligand-target structure interactions, we used the top docking pose of compound 6 and performed classical molecular dynamics (MD) simulations. Results showed that the most crucial residues at the binding site in the ligand binding are Phe138, Arg140, Glu229 and Tyr236. While Tyr236 constructs pi-pi stacking and hydrogen bonding interactions with the ligand other three residues form hydrogen bonds with the ligand via water bridges (Figure 6) Compound 6 maintains its interactions with the binding pocket residues during the simulations although the morpholine-1-yl-ethyl fragment has high fluctuation.

\section{Figure 6}

\section{Figure 7}

In conclusion, our studies led to identification of highly effective and potent novel eEF2K inhibitors for in vivo targeting of oncogenic eEF2K signaling in breast cancer and other cancers that have high eEF2K activity. Furthermore, our studies also provided evidence that our lead eEF2K inhibitors have superior binding capacity to eEF2K compared to the previously published

eEF2K inhibitor compounds (i.e, A484954, NH125, and TX-1918), ${ }^{19,27,28}$ suggesting that these compounds have potential for clinical applications as novel therapeutics. 


\section{MATERIALS AND METHODS}

Molecular modeling studies. Seventeen compounds (1-17) were prepared with the LigPrep module of Maestro at the neutral $\mathrm{pH}$. Prepared structures were geometrically optimized before the docking. Target protein was modeled and reported in our previous paper. This structure was used in docking. Flexible ligand docking was performed with the Glide/SP module of the Maestro. ${ }^{17}$ MD simulations were performed by Desmond at body temperature $(310 \mathrm{~K})$. Top-docking pose was used as input coordinates. An orthorhombic simulation box was used with explicit water models (TIP3P). $0.15 \mathrm{M} \mathrm{NaCl}$ salt is added to the system for the neutralization of the system. NPT ensemble was considered. Nose-Hoover temperature coupling and Martyna-Tobias-Klein pressure-coupling was used for keeping the system's temperature $(310 \mathrm{~K})$ and pressure (1.01 bar) constant throughout the simulations. 200-ns MD simulations were performed with 2 fs time steps.

Materials. Synthesis of designed compounds were performed by using commercially available reagents that were obtained from Merck, Fluka, and Sigma-Aldrich without further purification. To perform thin layer chromatography (TLC), silica gel plates $(0.25 \mathrm{~mm}, 60 \mathrm{GF} 254)$ were used. Column chromatography was performed on silica gel (70-230 mesh, Merck) using various solvents as eluent for the purification of the compounds. Melting points were determined by an X4 melting-point apparatus. A Perkin Elmer Spectrum 100 Fourier transform infrared (FTIR) spectrophotometer with attenuated total reflection (ATR) techniques, Nuclear Magnetic Resonance spectra $\left({ }^{1} \mathrm{H}\right.$ NMR and ${ }^{13} \mathrm{C}$ NMR) were recorded by an Agilent $600 \mathrm{MHz}$, JEOL 400 $\mathrm{MHz}$ and Varian $300 \mathrm{MHz}$ nuclear magnetic resonance (NMR) high-performance digital spectrometer, and a Shimadzu Scientific Instruments LC-MS MS 8040 liquid chromatography (LC)-tandem mass spectrometer were used for structural analysis. We indicated chemical shifts as $\delta$ values in parts per million (ppm) and coupling constants $(J$ ) in Hz. s (singlet), d (doublet), t (triplet), q(quartet), m (multiplet), dd (doublet of doublets) peaks were given. HRMS were determined with Agilent QTOF mass spectrometer 6530 series instruments and were performed in the ESI techniques at $70 \mathrm{eV}$.

General procedure for the synthesis of starting compounds (a-d). Ethyl 2-oxo-2 $\mathrm{H}$-chromene3-carboxylate (a), ethyl 6-methoxy-2-oxo- $2 \mathrm{H}$-chromene-3-carboxylate (b), 6-methoxy-2-oxo- $2 \mathrm{H}$ - 
chromene-3-carboxylic acid (c) and 6-methoxy-2-oxo-2H-chromene-3-carboxylic acid (d) were produced in high yields via Knoevenagel condensation reaction according to literature. ${ }^{37,50,51}$

General procedure for the synthesis of compounds (1-7). To a stirred solution of starting compounds (a or b) (1 eq.) in ethanol, substituted aliphatic amines (1.1 eq.) were added and the reaction mixture was heated and stirred at reflux temperature for $24 \mathrm{~h}$ and then allowed to cool down to room temperature. The resulting yellow crystals were filtered and dried. ${ }^{37,52}$

2-Oxo-N-(2-(pyrrolidine-1-yl)ethyl)-2H-chromene-3-carboxamide (1). Purified by silica-gel column chromatography $\left(\mathrm{CHCl}_{3} / \mathrm{MeOH}\right)$. White solid (Yield: $61 \%$; m.p. 127-130 $\left.{ }^{\circ} \mathrm{C}\right)$. IR (ATR, $\left.\mathrm{cm}^{-1}\right)$ v: $3323(\mathrm{~N}-\mathrm{H}), 3108,3045,2968-2749$, 1693, 1702, 1655, 1610. ${ }^{1} \mathrm{H}-\mathrm{NMR}$ (400 MHz, $\left.\mathrm{CDCl}_{3}\right): \delta 9.02(\mathrm{~s}, 1 \mathrm{H}, \mathrm{NH}), 8.89(\mathrm{~s}, 1 \mathrm{H}), 7.65$ (m, 2H), 7.37 (dd, 2H, J=14.7, 8.2 Hz), 3.59 (dd, 2H), $2.71(\mathrm{t}, 2 \mathrm{H}), 2.57(\mathrm{br}, 4 \mathrm{H}), 1.79(\mathrm{~m}, 4 \mathrm{H}) .{ }^{13} \mathrm{C}-\mathrm{NMR}\left(100 \mathrm{MHz}, \mathrm{CDCl}_{3}\right): \delta 161.39,154.48$, 148.22 , 133.92, 129.59, 125.96, 124.91, 119.02, 116.97, 116.59, 54.72, 54.00, 39.37, 23.47. LCMS/MS (ESI) $[\mathrm{M}+\mathrm{H}]^{+}=287.4$.

2-Oxo-N-(2-(piperidine-1-yl)ethyl)-2H-chromene-3-carboxamide (2). White solid (Yield: 41 \%; m.p: $\left.125-128{ }^{\circ} \mathrm{C}\right)$. IR (ATR, cm ${ }^{-1}$ ) v: 3336, 3046, 2951-2678, 1698, 1654, 1600. ${ }^{1} \mathrm{H}-\mathrm{NMR}(400$ $\left.\mathrm{MHz}, \mathrm{CDCl}_{3}\right): \delta 9.12(\mathrm{~s}, 1 \mathrm{H}, \mathrm{NH}), 8.87(\mathrm{~s}, 1 \mathrm{H}), 7.67-7.33(\mathrm{~m}), 3.73(\mathrm{t}, 2 \mathrm{H}), 3.54(\mathrm{dd}, 2 \mathrm{H}, J=11.7$, $6.4 \mathrm{~Hz}), 2.54(\mathrm{t}, 2 \mathrm{H}, J=6.5 \mathrm{~Hz}), 2.43(\mathrm{br}, 1 \mathrm{H}), 1.60(\mathrm{~m}, 1 \mathrm{H}) .{ }^{13} \mathrm{C}-\mathrm{NMR}\left(100 \mathrm{MHz}, \mathrm{CDCl}_{3}\right): \delta$ 161.01, 154.44, 148.39, 148.05, 147.12, 134.44, 129.62, 126.06, 124.71, 119.10, 116.95, 116.57, 57.50, 54.41, 25.33. LC-MS/MS (ESI) $[\mathrm{M}+\mathrm{H}]^{+}=301$.

N-(2-Morpholinoethyl)-2-oxo-2H-chromene-3-carboxamide (3). Washed with aseton/petroleum ether (4/1). White solid (Yield: $55 \%$; m.p: 138-141 ${ }^{\circ} \mathrm{C}$ ). IR (ATR, $\mathrm{cm}^{-1}$ ) v: 3324 , 3040, 2969-2744, 1742, 1694, 1653, 1605-1541. ${ }^{1} \mathrm{H}-\mathrm{NMR}$ (400 MHz, $\left.\mathrm{CDCl}_{3}\right): \delta 9.14$ (s, $\left.1 \mathrm{H}, \mathrm{NH}\right)$, $8.68(\mathrm{~s}, 1 \mathrm{H}), 7.69-7.34(\mathrm{ArH}), 3.73(\mathrm{t}, 2 \mathrm{H}), 3.57(\mathrm{q}, 2 \mathrm{H}), 2.59(\mathrm{t}, 2 \mathrm{H}), 2.51(\mathrm{t}, 2 \mathrm{H}) .{ }^{13} \mathrm{C}-\mathrm{NMR}(100$ $\left.\mathrm{MHz}, \mathrm{CDCl}_{3}\right): \delta 161.36,154.49,148.40,134.44,129.57,125.01,119.14,116.98,67.11,56.81$, 53.62, 36.84. LC-MS/MS (ESI) $[\mathrm{M}+\mathrm{H}]^{+}=303.4$.

6-Hydroxy-2-oxo-N-(2-(pyrrolidine-1-yl)ethyl)-2H-chromene-3-carboxamide (4). Yellow solid. (Yield: 76\%; m.p. 233-235 ${ }^{\circ} \mathrm{C}$ ). IR (ATR, cm ${ }^{-1}$ ) v: 3352, 3063, 2951-2811, 1706, 1650, 1616. ${ }^{1} \mathrm{H}-\mathrm{NMR}$ (300 MHz, DMSO): $\delta 9.95$ (s, 1H, OH), 8.90 (s, 1H, NH), 8.8 (s, 1H), 7.36-7.34 (d, 1H), $7.27(\mathrm{~d}, 1 \mathrm{H}), 7.18-7.15(\mathrm{dd}, 1 \mathrm{H}), 3.46(\mathrm{q}, 2 \mathrm{H}), 2.57(\mathrm{t}, 2 \mathrm{H}), 2.50(4 \mathrm{H}$, overlapped with DMSO peak), 1.74-1.67 (m, 4H). ${ }^{13} \mathrm{C}-\mathrm{NMR}$ (75 MHz, DMSO-d6): $\delta$ 161.52, 161.24, 154.59, 148.00, 
147.00, 122.82, 119.49, 119.08, 117.52, 114.23, 54.84, 53.95, 38.82, 23.64. LC-MS/MS (ESI) $[\mathrm{M}+\mathrm{H}]^{+}=303$.

6-Hydroxy-2-oxo- $N$-(2-(piperidine-1-yl)ethyl)-2H-chromene-3-carboxamide (5). Yellow solid (Yield: 83\%; m.p. 215-218 ${ }^{\circ}$ C). IR (ATR, $\mathrm{cm}^{-1}$ ) v: 3302, 3075, 3047, 2934-2856, 1696, 1653, 1570. ${ }^{1} \mathrm{H}-\mathrm{NMR}$ (300 MHz, DMSO): $\delta 9.92$ (br, 1H, OH), 8.94 (s, 1H, NH), 8,80 (s, 1H), 7.36-7.33 (d, 1H), 7.27 (d, 1H), 7.19-7.15 (dd, 1H), 3.44-3.38 (q, 2H), 2,46-2.38 (m, 6H), 1.55-1.48 (m, 4H), 1.40-1.39 (2H). ${ }^{13} \mathrm{C}-\mathrm{NMR}$ (75 MHz, DMSO): $\delta$ 161.41, 161.11, 154.68, 147.99, 147.82, 122.79, $119.49,119.05,117.51,114.23,57.25,54.31,36.99,26.09,24.53$. LC-MS/MS (ESI) $[\mathrm{M}+\mathrm{H}]^{+}=$ 317.4 .

6-Hydroxy-2-oxo-N-(2-(morpholine-1-yl)ethyl)-2H-chromene-3-carboxamide (6). Yellow crystals. (Yield: \% 44; m.p. 226-228 ${ }^{\circ}$ C). IR (ATR, $\mathrm{cm}^{-1}$ ) v: 3353, 3059, 2963-2824, 1702, 1649 , 1572. ${ }^{1} \mathrm{H}-\mathrm{NMR}$ (300 MHz, DMSO-d6): $\delta 9.91$ (s, 1H, OH), 8.96 (s, 1H, NH), 8.79 (s, 1H), 7.35 $(\mathrm{d}, 1 \mathrm{H}), 7.26(\mathrm{~d}, 1 \mathrm{H}), 7.15(\mathrm{dd}, 1 \mathrm{H}), 3.58(\mathrm{t}, 4 \mathrm{H}), 3.44(\mathrm{q}, 2 \mathrm{H}), 2.48(\mathrm{t}, 2 \mathrm{H}), 2.40(\mathrm{t}, 4 \mathrm{H}) .{ }^{13} \mathrm{C}-\mathrm{NMR}$ (75 MHz, DMSO): $\delta$ 161.47, 161.12, 154.68, 148.00, 147.82, 122.81, 119.48, 119.02, 117.51, 114.23, 66.74, 57.05, 53.54, 36.59. LC-MS/MS (ESI) $[\mathrm{M}+\mathrm{H}]^{+}=319.4$.

6-Hydroxy-2-oxo- $N$-(2-(piperazine-1-yl)ethyl)-2H-chromene-3-carboxamide (7). Yield: $50 \%$; m.p. 230-235 ${ }^{\circ} \mathrm{C}$ (decomposition)). IR (ATR, $\mathrm{cm}^{-1}$ ) v: 3301, 3256, 3052, 2967-2774, 1697, 1640. ${ }^{1} \mathrm{H}-\mathrm{NMR}$ (300 MHz, DMSO): $\delta 8.94$ (s, 1H), 8.80 (s, 1H, ArH), 7.37-7.34 (d, 1H, ArH), 7.28-7.27 (d, 1H, ArH), 7.20-7.16 (dd, 1H, ArH), 3.45-3.44 (q, 4H), 2.73-2.70 (t, 4H), 2.36 (br), 2.47-2.43 (t, 3H). ${ }^{13} \mathrm{C}-\mathrm{NMR}$ (75 MHz, DMSO-d6): $\delta 161.44,161.10,154.69,148.00,147.82,122.82,119.49$, $119.05,117.51,114.24,57.30,54.26,46.00,36.73$. LC-MS/MS (ESI) $[\mathrm{M}+\mathrm{H}]^{+}=318.4$.

Synthesis of compounds $(8,9)$. In the first step, $N$-Boc piperazine was synthesized according to reported method. ${ }^{53}$ In the second step, EDCI was used and the reaction was performed according to general amidation reaction. ${ }^{37,38}$ Then, the pure compound $(\mathbf{8})$ was treated with trifluoroacetic acid in dichloromethane $\left(\mathrm{CH}_{2} \mathrm{Cl}_{2}\right)$ at room temperature for $4 \mathrm{~h}$ to give compound 9.

t-Butil-4-(6-hydroxy-2-oxo-2H-chromene-3-carbonyl)piperazine-1-carboxylate (8). Colorless solid. Yield: 87\%; m.p: 180-185 ${ }^{\circ} \mathrm{C}$. IR (ATR, $\mathrm{cm}^{-1}$ ) v: 3037, 3002, 2976-2740, 1694. ${ }^{1} \mathrm{H}-\mathrm{NMR}$ (500 MHz, DMSO): 9.84 (s, 1H, OH), 8.10 (s, 1H, ArH), 7.28 (d, 2H, J=8.5 Hz, ArH), 7.08-7.06 $(2 \mathrm{H}, \mathrm{ArH}), 3.56\left(\mathrm{t}, 2 \mathrm{H}, \mathrm{CH}_{2}\right), 3.36-3.29\left(6 \mathrm{H}, \mathrm{CH}_{2}\right), 1.38$ (s, 9H). ${ }^{13} \mathrm{C}-\mathrm{NMR}(125 \mathrm{MHz}, \mathrm{DMSO}-$ d6): $\delta 163.91,158.30,154.42,147.37,142.86,124.92,121.42,119.26,117.54,113.67,79.96$, 46.56, 41.97, 28.29. LC-MSMS (ESI) $[\mathrm{M}+\mathrm{H}]^{+}=375$. 
6-Hydroxy-3-(piperazine-1-carbonyl)-2H-chromene-2-on trifluoroacetic acid (9). Colorless solid. Yield: 98\%; m.p: > $220{ }^{\circ} \mathrm{C}$. IR (ATR, $\mathrm{cm}^{-1}$ ) v: 3045, 2972-2497, 1711, 1667, 1616. ${ }^{1} \mathrm{H}-\mathrm{NMR}$ (500 MHz, DMSO): 9.94 (s, 1H, OH), 9.13 (s, 2H), 8.15 (s, 1H), 7.29 (s, 1H), 7.09 (d, 2H, J=12.7 $\mathrm{Hz}, \mathrm{ArH}), 3.78-3.58$ (t, 4H), 3.39 (br, 2H), 3.15-3.07 (t, 2H). ${ }^{13} \mathrm{C}-\mathrm{NMR}$ (125 MHz, DMSO-d6): $\delta$ 163.66, 158.33, 154.49, 147.31, 143.59, 124.14, 121.43, 119.11, 117.47, 113.34, 43.70, 43.39, 43.06, 38.66. LC-MS/MS (ESI) $[\mathrm{M}+\mathrm{H}]^{+}=275$.

General procedure for the synthesis of compounds (10-17). According to the procedure, ${ }^{39}$ the reaction was achieved using related aromatic amines including 5-amino-2-chloro-benzotrifluoride (10) and 4-aminophenylboronic acid pinacol ester (11-13). The purification of the compounds was performed by silica column chromatography.

N-(3-Chloro-4-(trifluoromethyl)phenyl)-6-hydroxy-2-oxo-2H-chromene-3-carboxamide (10). Yellow solid. Yield: 74\%; m.p.:265-267,5 ${ }^{\circ} \mathrm{C}$. IR (ATR, $\left.\mathrm{cm}^{-1}\right) v: 3658,3389,1692 .{ }^{1} \mathrm{H}-\mathrm{NMR}(500$ MHz, DMSO-d6): $\delta 10.95$ (s, 1H, OH), 10.01 (s, 1H, NH), 8.82 (s, 1H), 8.33 (d, 1H), 7.97 (d, 1H, $J=10.9 \mathrm{~Hz}), 7.72$ (d, 1H, J=8.7 Hz), 7.39 (d, 1H, J=8.9 Hz), 7.27 (d, 1H, J=2.8 Hz), 7.19 (dd, $J=8.9,2.8 \mathrm{~Hz}, 1 \mathrm{H}) .{ }^{13} \mathrm{C}-\mathrm{NMR}(125 \mathrm{MHz}, \mathrm{DMSO}-\mathrm{d} 6): \delta 161.31,160.66,154.83,148.12,147.92$, $137.75,132.59,127.39,125.42,124.12,123.30,122.23,120.03,119.16,117.64,114.19 .{ }^{19} \mathrm{~F}-\mathrm{NMR}$ (ppm) 61.41. LC-MS/MS (ESI) $[\mathrm{M}+\mathrm{H}]^{+}=384$.

4-(6-Hydroxy-2-oxo-2H-chromene-3-carboxamido)phenylboronic acid pinacol ester (11). Yellow solid. Yield: 31\%; m.p. $>250^{\circ} \mathrm{C}$. IR (ATR, $\mathrm{cm}^{-1}$ ) v: 3296, 3115, 3061, 2980-2850, 1689, 1648, 1615-1510, 1448-1372, 1351, 1140. ${ }^{1} \mathrm{H}-\mathrm{NMR}$ (500 MHz, DMSO-d6): $\delta 10.83$ (s, 1H, OH), 9.98 (s, 1H, NH), $8.82(\mathrm{~s}, 1 \mathrm{H}), 7.72$ (d, 1H, J=8.3 Hz), 7.67 (d, 1H, J=8.1 Hz), 7.39 (d, 1H, J=8.9 Hz), 7.29 (d, 1H, $J=2.8 \mathrm{~Hz}$ ), 7.19 (dd, 1H, J=9.0, $2.9 \mathrm{~Hz}) .{ }^{13} \mathrm{C}-\mathrm{NMR}(125 \mathrm{MHz}$, DMSO-d6): $\delta$ 161.16, 160.54, 154.61, 148.01, 147.38, 141.02, 135.73, 122.96, 120.01, 119.38, 117.47, 114.07, 84.07, 25.15. LC-MS/MS (ESI) $[\mathrm{M}+\mathrm{H}]^{+}=408$.

6-Methoxy-N-(4-(4,4,5,5-tetramethyl-1,3,2-dioxaborolane-2-yl)phenyl)-2-oxo-2H-chromene3-carboxamide (12). Yellow solid. Yield: 78\%; m.p. $>250{ }^{\circ} \mathrm{C}$. IR (ATR, $\mathrm{cm}^{-1}$ ) v: 3253, 3189, 3064, 2981-2844, 1688, 1662, 1355, 1136. ${ }^{1} \mathrm{H}-\mathrm{NMR}$ (400 MHz, DMSO-d6): $\delta 10.82$ (t, 1H, OH), 8.85 (s, 1H, NH), 7.72 (d, 1H, J=8.5 Hz), 7.66 (d, 1H, J=8.4 Hz), 7.57 (d, 1H, J=3.0 Hz), 7.49 (d, $1 \mathrm{H}, J=9.1 \mathrm{~Hz}), 7.35(\mathrm{dd}, 1 \mathrm{H}, J=9.1,3.0 \mathrm{~Hz}), 3.81(\mathrm{~s}, 3 \mathrm{H})$. LC-MS/MS (ESI) $[\mathrm{M}+\mathrm{H}]^{+}=422$.

6-Methoxy-N-(4-(boronic acid)phenyl)-2-oxo-2H-chromene-3 carboxamide (13). Yellow solid. Yield: $70 \%$; m.p. $>250^{\circ} \mathrm{C}$. IR (ATR, $\mathrm{cm}^{-1}$ ) v: 3508-3502(O-H), $3254(\mathrm{~N}-\mathrm{H}), 2998-2847$ (aliphatic 
C-H), 1697 (C=O). ${ }^{1} \mathrm{H}-\mathrm{NMR}$ (500 MHz, DMSO-d6): $\delta 10.75$ (s, 1H, -NH), 8.88 (s, 1H, OH), 8.00 (s, 2H), 7.79 (d, 1H, J=8.3 Hz), 7.67 (d, 1H, J=8.4 Hz), 7.58 (s, 1H), 7.49 (d, 1H, J=9.1 Hz), 7.387.33 (m, 1H), 3.82 (s, 3H). ${ }^{13} \mathrm{C}-\mathrm{NMR}$ (125 MHz, DMSO-d6): $\delta$ 160.97, 160.27, 156.35, 148.75, $147.54,139.71,135.52,122.44,120.24,119.52,119.04,117.54,112.20,56.39$. LC-MS/MS (ESI) $[\mathrm{M}+\mathrm{H}]^{+}=340$.

Genel procedure for the synthesis of compounds (14-17). The treatment of 3,4,5trimethoxybenzoic acid and 4-aminomethyl phenylboronic acid with EDCI and HOBt in DMF gave the compound $14 .{ }^{55}$ To a stirred solution of 4-aminophenylboronic acid pinacol ester (1 eq.) and triethylamine $\left(\mathrm{Et}_{3} \mathrm{~N}\right)$ (1 eq.) in diethyl ether, substituted benzoyl chloride was added and the mixture was stirred at room temperature for $2 \mathrm{~h}$. Solvent was evaporated under reduced pressure and water was added to quench the reaction. The resulting solids were filtered, washed with water and purified on a silica-gel column. Compound $\mathbf{1 7}$ was synthesized from compound $\mathbf{1 6}$ using $\mathrm{NaIO}_{4}$ in THF similar to compound $\mathbf{1 3}$.

$N$-(4-(4,4,5,5-Tetramethyl-1,3,2-dioxaborolan-2-yl)benzyl)-3,4,5-trimethoxybenzamide (14). White solid. Yield: 55\%; m.p. 108-112 ${ }^{\circ} \mathrm{C}$. IR (ATR, $\mathrm{cm}^{-1}$ ) v: 3427, 3104, 1663, 1332, 1120. ${ }^{1} \mathrm{H}$ NMR (400 MHz, CDCl $): \delta 7.79$ (d, 2H, J=7.8 Hz), 7.35 (d, 2H, J=7.8 Hz), 6.99 (s, 2H), 6.33 (s, $1 \mathrm{H}, \mathrm{NH}), 4.64(\mathrm{~d}, 2 \mathrm{H}, J=5.7 \mathrm{~Hz}), 3.86(\mathrm{~d}, 9 \mathrm{H}), 1.27(12 \mathrm{H}) .{ }^{13} \mathrm{C} \mathrm{NMR}\left(100 \mathrm{MHz}, \mathrm{CDCl}_{3}\right): \delta 167.10$, 152.97, 141.13, 135.22, 129.89, 127.48, 104.67, 83.76, 60.95, 56.40, 44.18, 24.90. LC-MS/MS (ESI) $[\mathrm{M}+\mathrm{H}]^{+}=428$.

$N$-(4-(4,4,5,5-tetramethyl-1,3,2-dioxaborolan-2-yl)phenyl)-3-(trifluoromethyl)benzamide (15). White solid. Yield: 74\%; m.p. 191-193 ${ }^{\circ} \mathrm{C}$. IR (KBR) v: 2980, 1647, 1523, 1359, 1122. ${ }^{1} \mathrm{H}-\mathrm{NMR}$ (300 MHz, DMSO): 10.65 (s, 1H, -NH), 7.77-8.40 (m, 7H), 1.39 (s, 12H). ${ }^{13} \mathrm{C}$ NMR (75 MHz, DMSO): $\delta$ 164.75, 142.23, 136.22, 132,46, 130,29, 129.79, 129.55, 128.75, 124.86, 120.05, 84.09, 25.25. HRMS (+ESI): C20H21BF3NO3 [M+H] ${ }^{+}$: calculated: 392,1647; found: 392,1676 .

4-Nitro-N-(4-(4,4,5,5-tetramethyl-1,3,2 dioxaborolan-2-yl)phenyl)benzamide (16). Yellow. Yield: 44\%; m.p. 218-221 ${ }^{\circ} \mathrm{C}$. IR (KBR) v: 2980, 1654, 1525. ${ }^{1} \mathrm{H}$ NMR (300 MHz, DMSO): 10.64 (s, 1H, -NH), 8.35 (d, 1H, ArH), 8.17 (d, 1H, ArH), $7.81(\mathrm{~d}, 1 \mathrm{H}, \operatorname{ArH}), 7.67(\mathrm{~d}, 1 \mathrm{H}, \operatorname{ArH}), 1.28(\mathrm{~s}$, $\left.12 \mathrm{H}, \mathrm{CH}_{3}\right) .{ }^{13} \mathrm{C}$ NMR (75 MHz, DMSO): $\delta$ 164.68, 149.82, 142.16, 141.06, 135.80, 129.89, 
124.15, 120.03, 81.84, 40.98, 25.30. HRMS (+ESI): C19H21BN2O5 $[\mathrm{M}+\mathrm{H}]^{+}:$calculated: 369,1624; found: 369,1670 .

4-(4-Nitrobenzamido)phenylboronic acid (17). Yellow. Yield: 19\%; m.p. 266-269 ${ }^{\circ} \mathrm{C}$. IR (KBR) v: 2918, 1656, 1512. ${ }^{1} \mathrm{H}$ NMR (300 MHz, DMSO): 11.10 (s, 1H, -NH), 10.08 (s, 1H, -OH), $9.11(\mathrm{~d}, 1 \mathrm{H}, \mathrm{ArH}), 8.92(\mathrm{~d}, 1 \mathrm{H}, \mathrm{ArH}), 8.30(\mathrm{~d}, 1 \mathrm{H}, \mathrm{ArH}), 7.52(\mathrm{~d}, 1 \mathrm{H}, \mathrm{ArH}),{ }^{13} \mathrm{C} \mathrm{NMR}(75 \mathrm{MHz}$, DMSO): $\delta 163.79,154.69,149.58,141.45,130.81,129.63,124.08,122.93,115.66$.

Determination of eEF2K inhibition in MDA-MB-231 cells. To determine the inhibition of downstream targets (pEF2) of eEF2K, western blotting was used. The method was carried out according to our previously reported study. ${ }^{17}$ Briefly, MDA-MB-231 cells were treated with the selected compounds at 1 and $2.5 \mu \mathrm{M}$ concentrations for $2 \mathrm{~h}$ treatment. Following the transfer of the proteins to membrane, specific antibodies were used for the detection of expression levels. ${ }^{55}$

Conclusions. In our recent study, homology modeling studies of eEF2K were performed and 3D structure of the target protein was developed by us and used for designing of new eEF2K inhibitors. $2 \mathrm{H}$-Chromene-3-carboxamide compounds were found highly effective in breast cancer cells. Herein, a series of aliphatic and aromatic amide compounds including coumarin scaffold (thirteen compounds) and phenyl ring (four compounds) that contain significant and therapeutically active groups such as boronic acids and heterocyclic amines including pyrrolidine, morpholine, piperidine, piperazine were designed, synthesized and then, tested in breast cancer cells. The good correlation was obtained between the in silico and in vitro results. These novel compounds, especially $(\mathbf{1}, \mathbf{3}, \mathbf{4}, \mathbf{6}, \mathbf{7}, \mathbf{1 1})$ as eEF2K inhibitors have better inhibition than the other known inhibitors to be used in potential applications. In addition, in this study, we reported new and highly effective coumarin derivatives compared to our reported compounds. ${ }^{17}$ Overall, this study will lead to a new avenue for further studies.

Declaration of Competing Interest. The authors declare that they have no known competing financial interests.

Acknowledgements. This study was supported by The Scientific and Technological Research Council of Turkey (TUBITAK, Project No 215S008). FCO also thanks TUBITAK for scholarships 
(215S008 Project and BIDEB 2214A program). The authors thank to Çanakkale Onsekiz Mart University-COBILTUM Center Laboratory and Cankiri Karatekin University Research Center Laboratory and DEVA Holding A.Ş. for spectral analysis. NK and BO were supported by The University of Texas-MD Anderson Bridge funding and NIH-NCI R01CA244344 grants

\section{Appendix A. Supplementary data}

Supplementary data to this article can be found online at https://

\section{References}

1. Schiltz GE. (2014). Heteroatom Manipulation in Comprehensive Organic Synthesis II (Second Edition), 6.13 Use of Carbonyl Derivatives for Heterocyclic Synthesis, Volume 6, 555-572. Elsevier. doi:10.1016/B978-0-08-097742-3.00621-2.

2. Martins P, Jesus J, Santos S, Raposo LR, Roma-Rodrigues C, Baptista PV, Fernandes AR. (2015). Heterocyclic Anticancer Compounds: Recent Advances and the Paradigm Shift towards the Use of Nanomedicine's Tool Box. Molecules 20:16852-16891. doi: 10.3390/molecules200916852.

3. Moldoveanu SC, (2019). Chapter 21 Pyrolysis of Aromatic Heterocyclic Compounds, Editor(s): Moldoveanu SC, Techniques and Instrumentation in Analytical Chemistry, Elsevier, 28, 2010, 643-675. https://doi.org/10.1016/S0167-9244(09)02821-2

4. Barmade MA, Ghuge RB. (2018). Chapter 1. Vicinal Diaryl Heterocyclic System: A Privileged Scaffold in the Discovery of Potential Therapeutic Agents. 1-20. https://doi.org/10.1016/B978-0-08-102237-5.00001-8

5. Bansal Y, Sethi P, Bansal G. (2013). Coumarin: a potential nucleus for antiinflammatory molecules. Med Chem Res 22:3049-3060. https://doi.org/10.1007/s00044-012-0321-6

6. Shi Y, Zhou CH. (2011). Synthesis and evaluation of a class of new coumarin triazole derivatives as potential antimicrobial agents, Bioorg Med Chem Lett 21:956-961. https://doi.org/10.1016/j.bmcl.2010.12.059

7. Bhattacharya S. (2011). Natural antimutagens: a review, J Med Plants Res 5: 116-121. DOI: 10.3923/rjmp.2011.116.126 
8. Klenkar J, Molnar M. (2015). Natural and synthetic coumarins as potential anticancer agents. J Chem Pharm Res 7:1223-1238. https://www.jocpr.com/articles/natural-andsynthetic-coumarins-as-potential-anticancer-agents.pdf

9. Kontogiorgis C, Detsi A, Hadjipavlou-Litina D. (2012). Coumarin based drugs: a patent review (2008-present). Expert Opin Ther Pat 22:437-454. doi: $10.1517 / 13543776.2012 .678835$

10. Singh RK, Lange TS, Kim KK, Brard L. (2011). A coumarin derivative (RKS262) inhibits cell-cycle progression, causes proapoptotic signaling and cytotoxicity in ovarian cancer cells. Invest New Drugs 29:63-72. doi: 10.1007/s10637-009-9335-4

11. Chia-Hsiung C, Ku-Chung L, Wai-Theng W, Yen-Fang X, Lin C. (2014). Induction of ROS-independent JNK-activation-mediated apoptosis by a novel coumarin derivative, DMAC, in human colon cancer cells. Chem Bio Int 218: 42-49. doi: 10.1016/j.cbi.2014.04.015.

12. Saidu N, Valente S, Emilie B, Gilbert K, Denyse B, Mathias M. (2012). Coumarin polysulfides inhibit cell growth and induce apoptosis in HCT116 colon cancer cells. Bioog Med Chem 4: 1584-1593. https://doi.org/10.1016/j.bmc.2011.12.032

13. Thakur A, Singla R, Jaitak V. (2015). Coumarins as anticancer agents: A review on synthetic strategies, mechanism of action and SAR studies. Eur J Med Chem 101:476-495. doi: 10.1016/j.ejmech.2015.07.010.

14. Beinema M, Brouwers JR, Schalekamp T, Wilffert B. (2008). Pharmacogenetic differences between warfarin, acenocoumarol and phenprocoumon. Thromb Haemost. 100(6):1052-7. doi:10.1160/TH08-04-0116

15. Hu Y-Q, Xu Z, Zhang S, Wu X, Ding J-W, Lv Z-S, Feng L-S. (2017). Recent developments of coumarin-containing derivatives and their anti-tubercular activity, Eur J Med Chem 136, 122-130. DOI: 10.1016/j.ejmech.2017.05.004

16. Kaur M, Kohli S, Sandhu S, Bansal Y, Bansal G. (2015). Coumarin: a promising scaffold for anticancer agents. Anticancer Agents Med Chem 15(8):1032-48. doi: $10.2174 / 1871520615666150101125503$

17. Comert Onder F, Durdagi S, Sahin K, Ozpolat B, Ay M. (2020) Design, Synthesis, and Molecular Modeling Studies of Novel Coumarin Carboxamide Derivatives as eEF-2K Inhibitors. J Chem Inf Model 60:1766-1778. https://doi.org/10.1021/acs.jcim.9b01083 
18. Küpeli Akkol E, Genç Y, Karpuz B, Sobarzo-Sánchez E, Capasso R. (2020). Coumarins and Coumarin-Related Compounds in Pharmacotherapy of Cancer. Cancers 12, 1959. doi:10.3390/cancers12071959

19. Devkota AK, Tavares CDJ, Warthaka M, Abramczyk O, Marshall KD, Kaoud TS, Gorgulu K, Ozpolat B, Dalby KN. (2012). Investigating the kinetic mechanism of inhibition of elongation factor 2 kinase by NH125: evidence of a common in vitro artifact. Biochemistry 51:2100-2112. doi: 10.1021/bi201787p.

20. Bayraktar R, Pichler M, Kanlikilicer P, Ivan C, Bayraktar E, Kahraman N, Aslan B, Oguztuzun S, Ulasli M, Arslan A, Calin GA, Lopez G, Ozpolat B. (2017). MicroRNA 603 acts as a tumor suppressor and inhibits triple negative breast cancer tumorigenesis by targeting elongation factor 2 kinase. Oncotarget 8:1164111658. doi: 10.18632/oncotarget.14264.

21. Ashour AA, Abdel-Aziz AA, Mansour AM, Alpay SN, Huo L, Ozpolat B. (2014). Targeting elongation factor-2 kinase (eEF-2K) induces apoptosis in human pancreatic cancer cells. Apoptosis 19,1:241-58. doi: 10.1007/s10495-013-0927-2.

22. Bircan, H. A.; Gurbuz, N.; Pataer, A.; Caner, A.; Kahraman, N.; Bayraktar, E.; Bayraktar, R.; Erdogan, M. A.; Kabil, N.; Ozpolat, B. (2018). Elongation factor-2 kinase (eEF-2K) expression is associated with poor patient survival and promotes proliferation, invasion and

tumor growth of lung cancer. Lung Cancer 124, 31-39. doi: 10.1016/j.lungcan.2018.07.027.

23. Tekedereli I, Alpay SN, Tavares CD, Cobanoglu ZE, Kaoud TS, Sahin I, Sood AK, LopezBerestein G, Dalby KN, Ozpolat B. (2012). Targeted Silencing of Elongation Factor 2 Kinase Suppresses Growth and Sensitizes Tumors to Doxorubicin in an Orthotopic Model of Breast Cancer, PlosOne 7:1-12. doi:10.1371/journal.pone.0041171

24. Asik E, Akpinar Y, Caner A, Kahraman N, Guray T, Volkan M, Albarracin C, Pataer A, Arun B, Ozpolat B. (2019). EF2-kinase targeted cobalt-ferrite siRNA-nanotherapy suppresses BRCA1-mutated breast cancer. Nanomedicine (Lond) 14(17):2315-2338. https://doi.org/10.2217/nnm-2019-0132 
25. Bayraktar R, Ivan C, Bayraktar E, Kanlikilicer P, Kabil NN, Kahraman N, Mokhlis HA, Karakas D, Rodriguez-Aguayo C, Arslan A, Sheng J, Wong S, Lopez-Berestein G, Calin GA, Ozpolat B. (2018). Dual suppressive effect of miR-34A on the FOXM1/ EEF2-kinase axis regulates triple-negative breast cancer growth and invasion. Clin Cancer Res 24:42254241. doi: 10.1158/1078-0432.CCR-17-1959.

26. Ashour AA, Gürbüz N, Alpay SN, Abdel-Aziz HAA, Abdel-Aziz AA, Mansour AM, Huo L, Ozpolat B. (2014). Elongation factor-2 kinase regulates TG2/ $\beta 1$ integrin/Src/uPAR pathway and epithelial-mesenchymal transition mediating pancreatic cancer cells invasion. J Cellular and Mol Med 18: 2235-2251. doi: 10.1111/jcmm.12361.

27. Cho S, Koketsu M, Ishihara H, Matsushita M, Nairn AC, Fukazawa H, Uehara Y. (2000). Novel compounds,

"1,3-selenazine derivatives" as specific inhibitors of eukaryotic elongation factor-2 kinase. Biochim Biophys Acta 1475, 207-215. https://doi.org/10.1016/S03044165(00)00061-1

28. Devkota AK, Edupuganti R, Yan C, Shi Y, Jose J, Wang Q, Kaoud TS, Cho EJ, Ren P, Dalby KN. (2014). Reversible covalent inhibition of eEF-2K by carbonitriles. ChemBioChem 15:24352442. https://doi.org/10.1002/cbic.201402321

29. Ay M, Ozpolat B, Comert Onder F, Taşkın Tok T, Bellur Atıcı E, Karlıga B, Kandemir H, Cagir A, Sahiner N, Tatar G. (2019). EF2 Kinase Enzyme Inhibiting Novel Compounds. WO2019/240701

A1. https://patentscope.wipo.int/search/en/detail.jsf?docId=WO2019240701

30. Yang F, Zhu M, Zhang J, Zhou H. (2018). Synthesis of biologically active boroncontaining compounds. Med Chem Commun 9:201. DOI: 10.1039/c7md00552k

31. Smoum R, Rubinstein A, Dembitsky VM, Srebnik M. (2012). Boron Containing Compounds as Protease Inhibitors. Chem Rev 112,7:4156-4220. https://doi.org/10.1021/cr608202m

32. Fernandes GFS, Denny WA, Santos JLD. (2019). Boron in drug design: Recent advances in the development of new therapeutic agents. Eur J Med Chem 179, 791-804. doi: 10.1016/j.ejmech.2019.06.092. 
33. Trippier PC, McGuigan C. (2010). Boronic acids in medicinal chemistry: anticancer, antibacterial and antiviral Applications. Med Chem Commun 1:183-198. DOI: 10.1039/c0md00119h

34. Sastry GM, Adzhigirey M, Day $\mathrm{T}$, Annabhimoju R, Sherman W. (2013). Protein and ligand preparation: parameters, protocols, and influence on virtual screening enrichments. J. Comput.-Aided Mol. Des 27:221. doi: 10.1007/s10822-013-9644-8.

35. Jorgensen WL, Tirado-Rives J. (1988). The OPLS Force Field for Proteins. Energy Minimizations for Crystals of Cyclic Peptides and Crambin. J Am Chem Soc 110:1657-1666. https://doi.org/10.1021/ja00214a001

36. Shelly JC, Cholleti A, Frye LL, Greenwood JR, Timlin MR, Uchimaya M. (2007). Epik: a software program for $\mathrm{pK}(\mathrm{a})$ prediction and protonation state generation for drug-like molecules. $J$ Comput.Aided Mol Des 21:681-691. doi: 10.1007/s10822-007-9133-z.

37. Onder FC, Kahraman N, Atici EB, Cagir A, Kandemir H, Tatar G, Tok TT, Karliga B, Durdagi S, Ay M, Ozpolat B. (2020). Target-driven design of a coumarinyl chalcone scaffold based novel EF2 Kinase inhibitor suppresses breast cancer growth in vivo. bioRxiv preprint doi: https://doi.org/10.1101/2020.11.06.371062

38. Kurishita Y, Kohira T, Ojida A, Hamachi I. (2010). Rational Design of FRET-Based Ratiometric Chemosensors for in Vitro and in Cell Fluorescence Analyses of Nucleoside Polyphosphates. J Am Chem Soc 132, 13290-13299. https://doi.org/10.1021/ja103615z

39. Baenteli R, Cooke NG, Zecri F, Smith AB. (2008). Chromene S1P1 Receptor Antagonist. WO2008092930 (A1). https://patents.google.com/patent/WO2008092930A1/en

40. Das BC, Thapa P, Karki R, Schinke C, Das S, Kambhampati S, Banerjee SK, Van Veldhuizen P, Verma A, Weiss LM, Evans T. (2013). Boron chemicals in diagnosis and therapeutics. Future Med Chem 5(6):653-76. doi: 10.4155/fmc.13.38.

41. Albers HMHG, Hendrick LJD, Rob JP van Tol, Hausmann J, Perrakis A and Ovaa H. (2011). Structure-Based Design of Novel Boronic Acid-Based Inhibitors of Autotaxin. $J$ Med Chem 54,13:4619-4626. https://doi.org/10.1021/jm200310q 
42. Amin KM, Eissa AAM, Abou-Seri SM, Awadallah F M, Hassan GS. (2013). Synthesis and biological evaluation of novel coumarin-pyrazoline hybrids endowed with phenylsulfonyl moiety as antitumor agents. Eur J Med Chem 60, 187-198. doi: 10.1016/j.ejmech.2012.12.004.

43. Chimenti F, Secci D, Bolasco A, Chimenti P, Bizzarri B, Granese A, Carradori S, Yañez M, Orallo F, Ortuso F, Alcaro S. (2009). Synthesis, molecular modeling, and selective inhibitory activity against human monoamine oxidases of 3-carboxamido-7-substituted coumarins. J Med Chem 52:1935-1942. doi: 10.1021/jm801496u.

44. Sepay N, Guha C, Kool A, Mallik AK. (2015). An efficient three component synthesis of coumarin-3-carboxamide by use of nanoparticles as magnetically separable catalysts. RSC Adv 5: 70718. DOI: $10.1039 / \mathrm{c} 5 \mathrm{ra} 13932 \mathrm{e}$

45. Ma J, Chen D, Lu K, Wang L, Han X, Zhao Y, Gong P. (2014). Design, synthesis, and structure-activity relationships of novel benzothiazole derivatives bearing the ortho-hydroxy N-carbamoyl hydrazone moiety as potent antitumor agents. Eur $J$ Med Chem 86:257-269. https://doi.org/10.1016/j.ejmech.2014.08.058

46. Yao D, Wang J, Wang G, Jiang Y Shang L, Zhao Y, Huang J, Yang S, Wang J, Yu Y. (2016). Design, synthesis and biological evaluation of coumarin derivatives as novel acetylcholinesterase inhibitors that attenuate $\mathrm{H} 2 \mathrm{O} 2$-induced apoptosis in SH-SY5Y cells. Bioorg Chem 68:112-123. doi: 10.1016/j.bioorg.2016.07.013.

47. Vanzolini KL, Vieira LCC, Corrêa AG, Cardoso CL, Cass QB. Acetylcholinesterase Immobilized Capillary Reactors-Tandem MassSpectrometry: An On-Flow Tool for Ligand Screening. (2013). J Med Chem 56, 2038-2044. https://doi.org/10.1021/jm301732a

48. Tehrani MB, Rezaei Z, Asadi M, Behnammanesh H, Nadri H, Afsharirad F, Moradi A, Larijani B, Mohammadi-Khanaposhtani M, Mahdavi M. (2013). Design, Synthesis, and Cholinesterase Inhibition Assay of Coumarin-3-carboxamide-N-morpholine Hybrids as 
New Anti-Alzheimer Agents. Chem Biodivers 16(7):e1900144. doi: $10.1002 / \mathrm{cbdv} .201900144$.

49. Tanoli NU, Sheraz AK, Tanoli AG. Ferreira, Mehmood M, Gul S, Monteiro JL, Lucas CC, Venâncio T, Correa AG, Ul-Haq Z. (2018). Characterization of the interactions between coumarin-derivatives and acetylcholinesterase: Examination by NMR and docking simulations. J Mol Mod 24: 207. doi: 10.1007/s00894-018-3751-3.

50. Cerqueira NMFSA, Rodrigues LM, Oliveira-Campos AMF, Melo de Carvalho LH, Coelho PJ, Dubest R, Aubard J, Samat A, Guglielmetti R. (2003). Synthesis and reactivity of photochromic $2 \mathrm{H}$-chromenes based on 3-carboxylated coumarins. Helvetica Chimica Acta 86(9): 3244-3253. https://doi.org/10.1002/hlca.200390264

51. Wells J, Renslo AR, Wolan D, Zorn J. (2009). (a) Activators of executioner procaspases 3, 6 and 7. WO 2009089508 A1. https://patents.google.com/patent/WO2009089508A1/en

52. García-Baéz EV, Martínez-Martínez FJ, Hôpfl H, Padilla-Martínez II. (2003). ð-Stacking Interactions and CsHâââX (X ) O, Aryl) Hydrogen Bonding as Directing Features of the Supramolecular Self-Association in 3-Carboxy and 3-Amido Coumarin Derivatives. Crystal Growth \& Design, 3, 1:36-45. https://doi.org/10.1021/cg0255826

53. Wang J, Dai D, Qiu Q, Deng X, Lin H, Qian H, Huang W. (2015). Evaluation of Antiinflammatory and Analgesic Effects of Synthesized Derivatives of Ibuprofen. Chem Biol Drug Des 85:623-632. doi: 10.1111/cbdd.12316.

54. Morera E, Di Marzo V, Monti L, Allarà M, Moriello AS, Nalli M, Ortar G, De Petrocellis L. (2016). Arylboronic acids as dual-action FAAH and TRPV1 ligands. Bioorganic and Medicinal hemistry Letters 26, 1401-1405. https://doi.org/10.1016/j.bmcl.2016.01.071

55. Kabil N, Bayraktar R, Kahraman N, Mokhlis HA, Calin GA, Lopez-Berestein G, Ozpolat B. (2018). Thymoquinone inhibits cell proliferation, migration, and invasion by regulating the elongation factor 2 kinase (eEF-2K) signaling axis in triple-negative breast cancer. Breast Cancer Res Treat 171:593-605. doi: 10.1007/s10549-018-4847-2. 


\section{Table of Contents}

Table 1. The docking scores of the 17 synthesized compounds calculated by Glide/SP.

\begin{tabular}{|c|c|c|c|}
\hline $\begin{array}{c}\text { Compound } \\
\text { No }\end{array}$ & $\begin{array}{c}\text { Docking score } \\
\text { (kcal/mol) }\end{array}$ & Compound No & $\begin{array}{c}\text { Docking score } \\
\text { (kcal/mol) }\end{array}$ \\
\hline $\mathbf{1}$ & -5.678 & $\mathbf{1 0}$ & -4.026 \\
\hline $\mathbf{2}$ & -6.258 & $\mathbf{1 1}$ & $\mathbf{- 6 . 1 2 1}$ \\
\hline $\mathbf{3}$ & -6.121 & $\mathbf{1 2}$ & -5.816 \\
\hline $\mathbf{4}$ & $\mathbf{- 7 . 3 3 4}$ & $\mathbf{1 3}$ & -5.920 \\
\hline $\mathbf{5}$ & $\mathbf{- 7 . 2 0 8}$ & $\mathbf{1 4}$ & -5.471 \\
\hline $\mathbf{6}$ & $\mathbf{- 7 . 0 1 4}$ & $\mathbf{1 5}$ & -4.524 \\
\hline $\mathbf{7}$ & -5.870 & $\mathbf{1 6}$ & -4.578 \\
\hline $\mathbf{8}$ & -6.502 & $\mathbf{1 7}$ & -4.698 \\
\hline $\mathbf{9}$ & -6.546 & & \\
\hline
\end{tabular}


Table 2. The structures of compounds 10-17

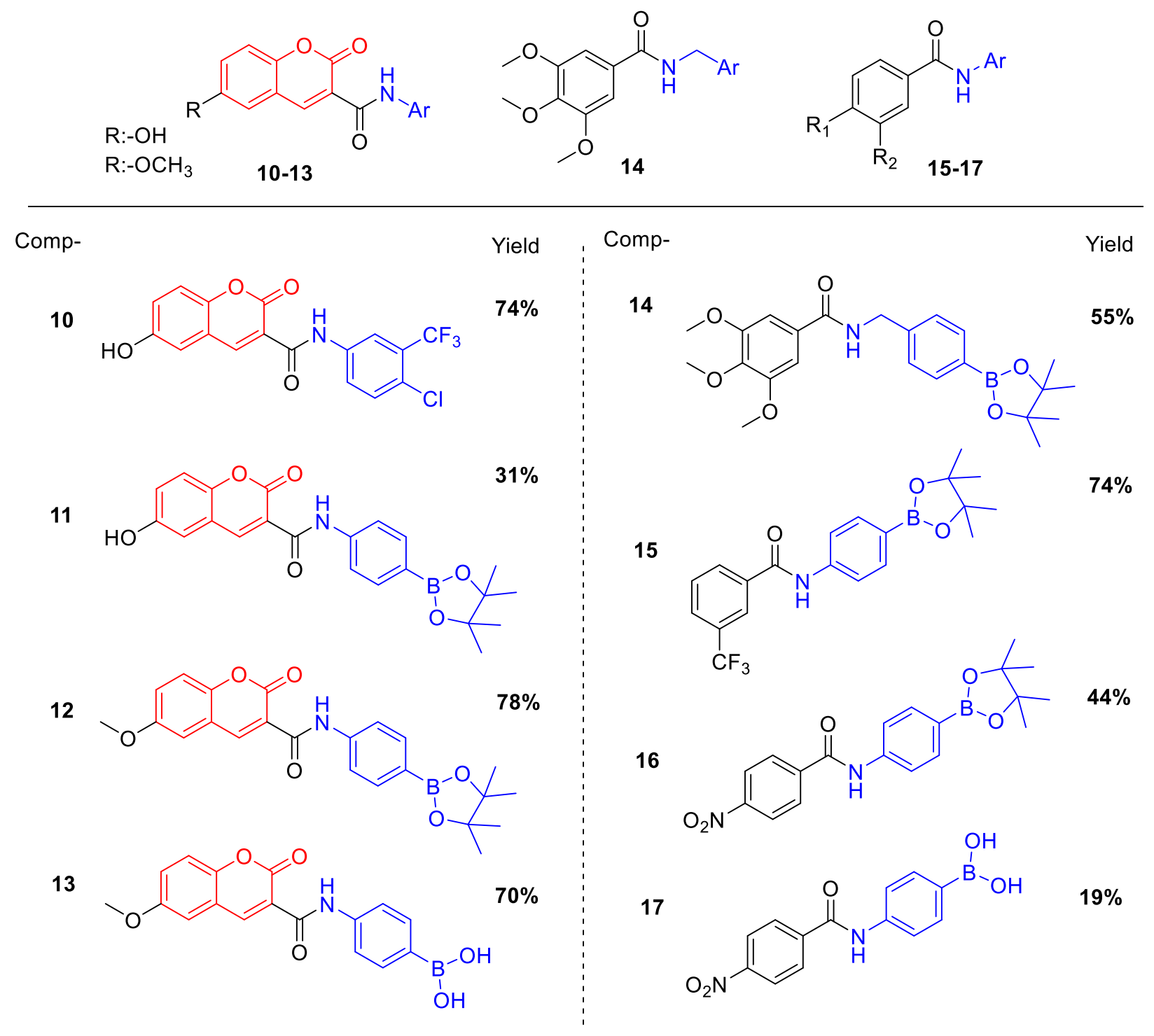




\section{Figure Captions}

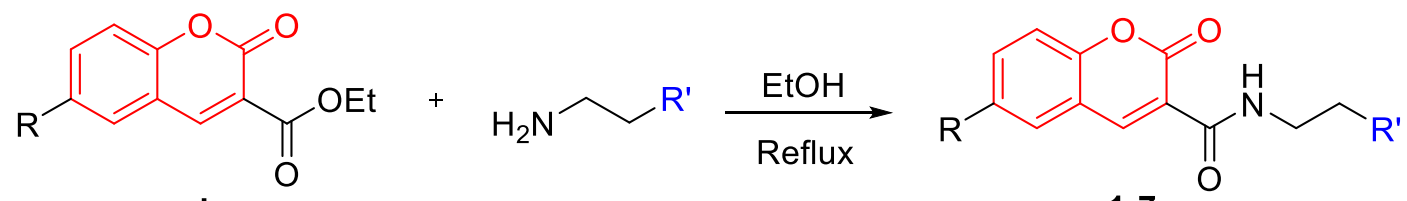

$\mathrm{R}:-\mathrm{OH} \quad \mathbf{a}, \mathbf{b}$

$1-7$

$\mathrm{R}:-\mathrm{H}$

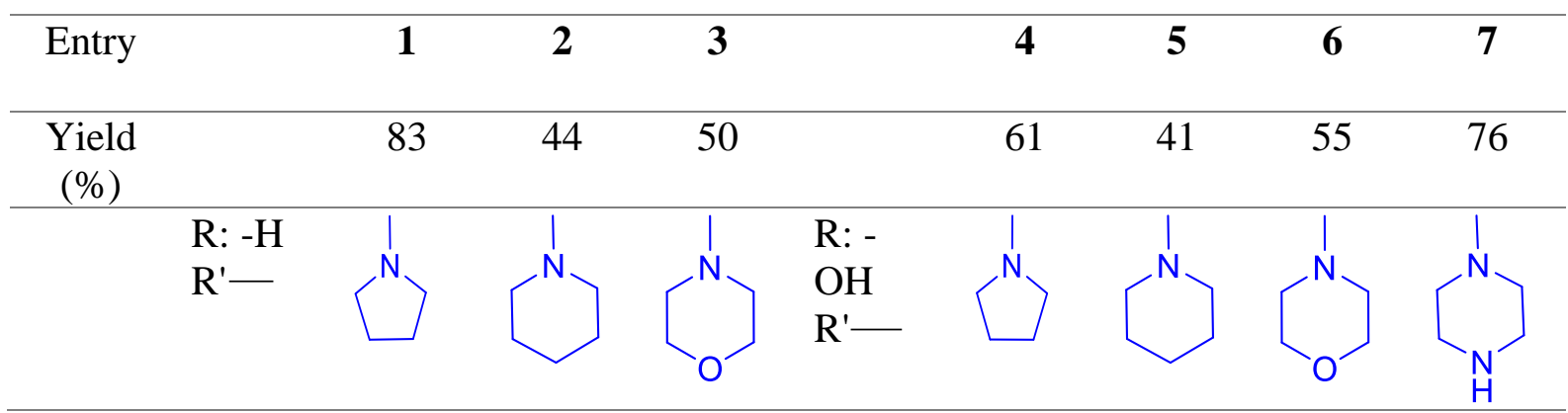

Figure 1. The general reaction for synthesis of compounds 1-7

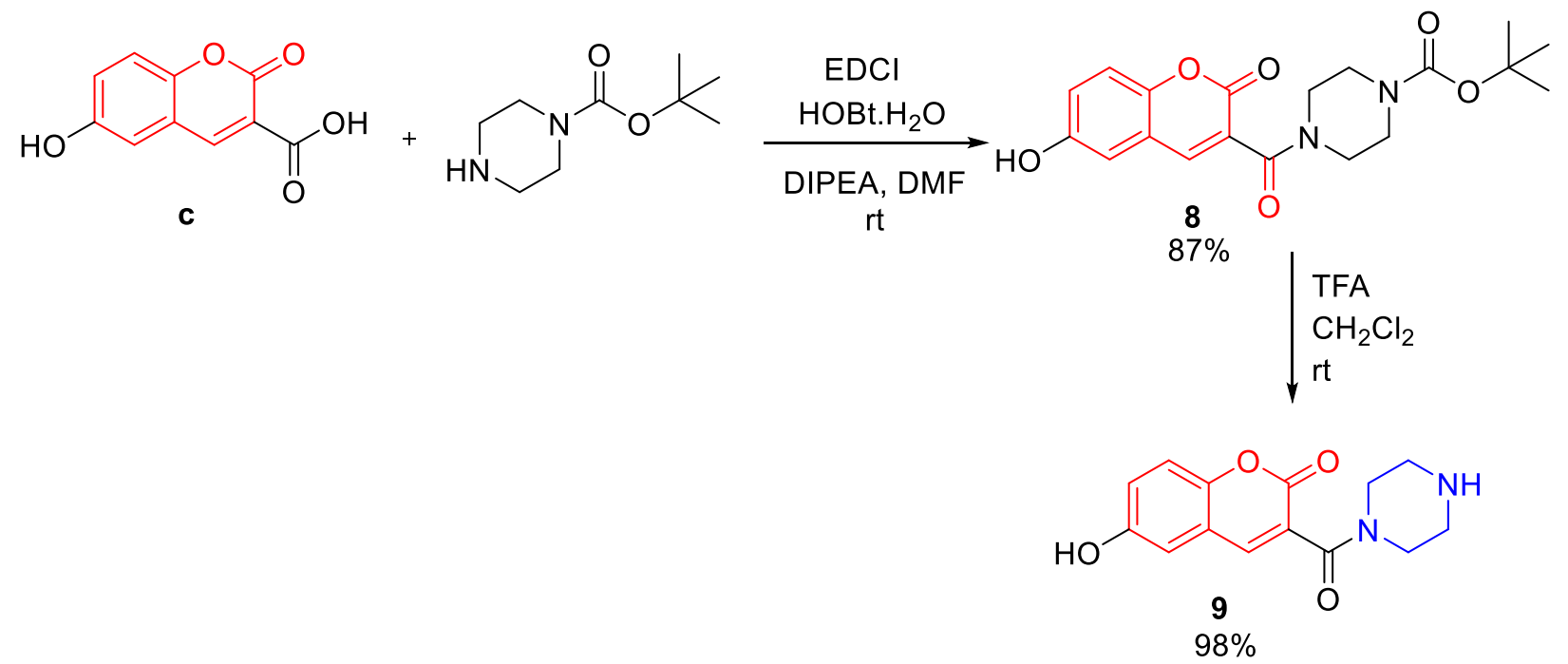

Figure 2. The general reaction for synthesis of compounds $\mathbf{8 , 9}$. 


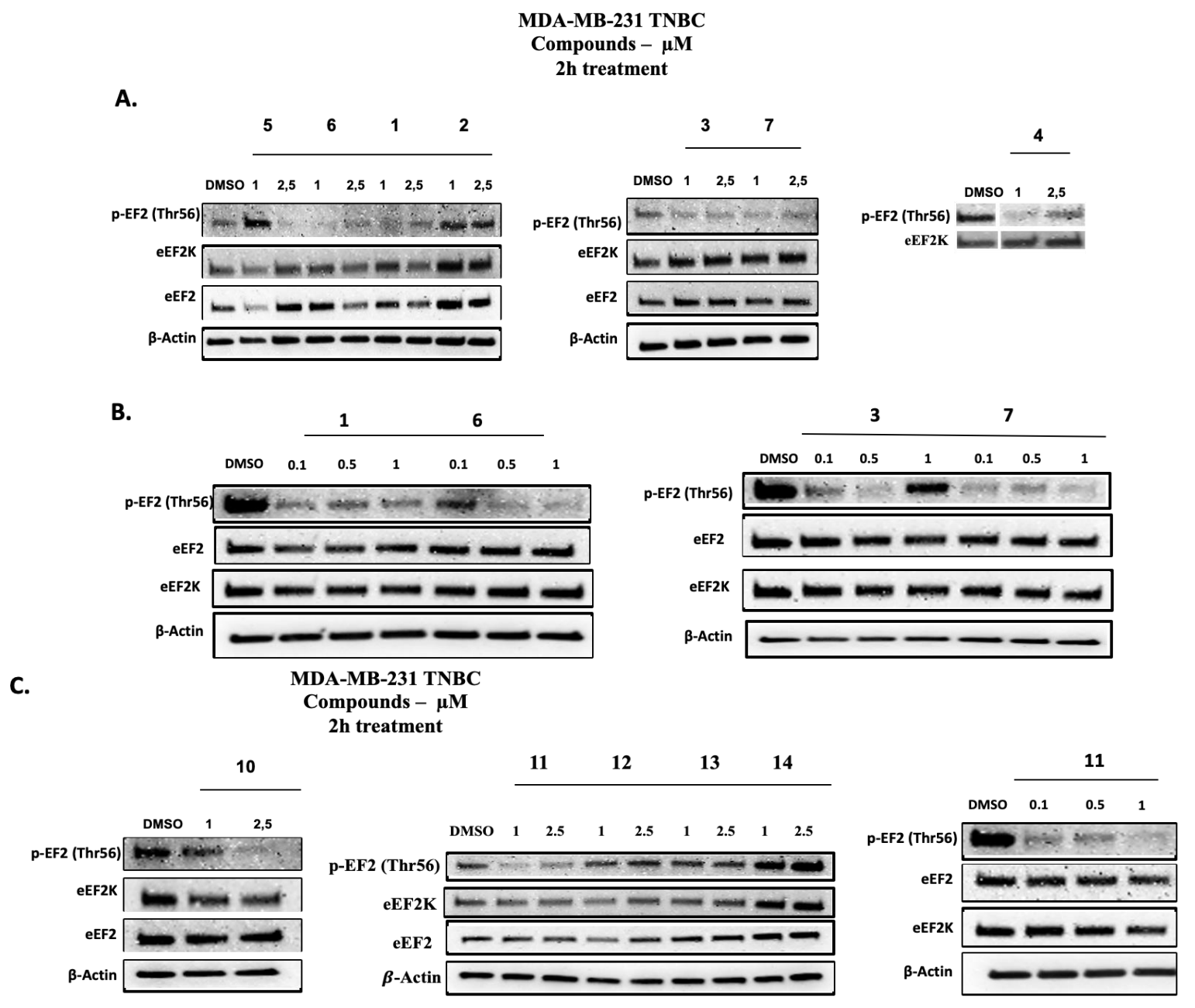

Figure 3. Evaluation of newly synthesized compounds for eEF-2K inhibition in breast cancer cells. MDA-MB-231 cells were treated for $2 \mathrm{~h}$ with compounds $\mathbf{1 , 3 , 4 , 6 , 7 , 1 1}$ in the range of 0.1-2.5 $\mu \mathrm{M}$ to be analyzed for pEF2 (Thr56) levels by Western blot analysis. 

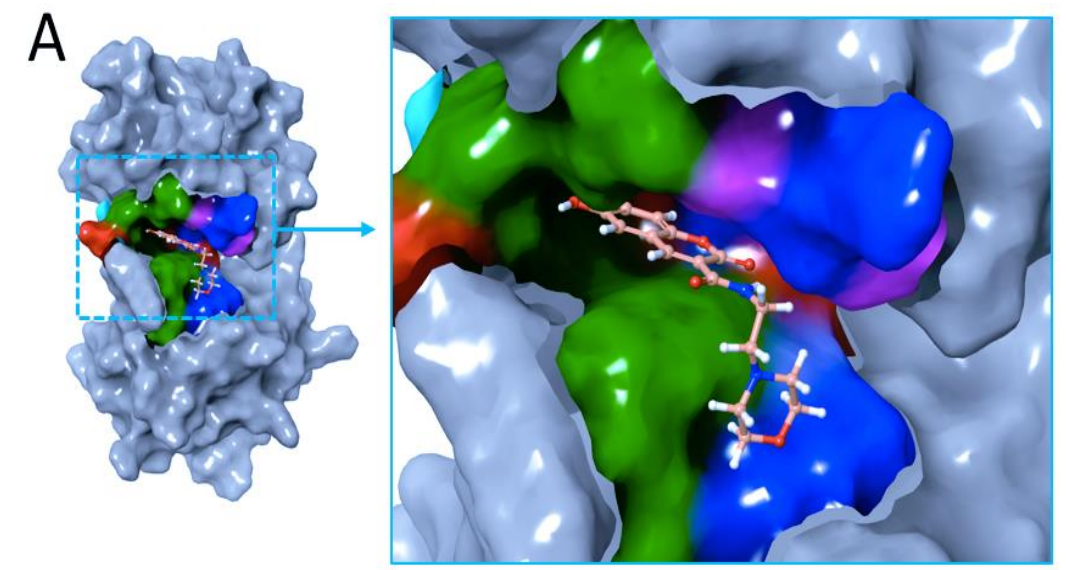

B

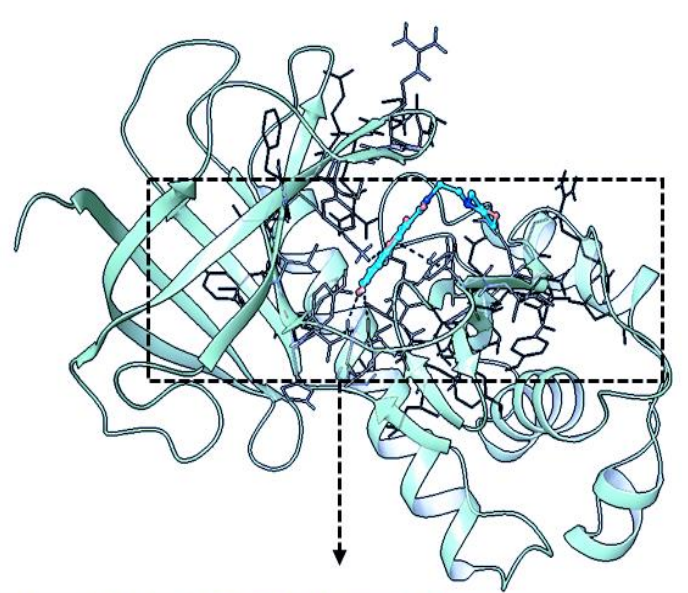

C

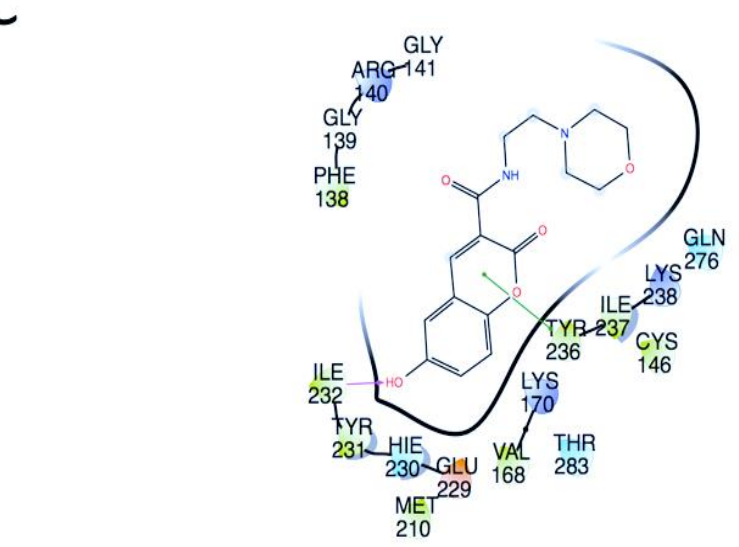

8 Charged (negative)

Hycrophobic
Metal
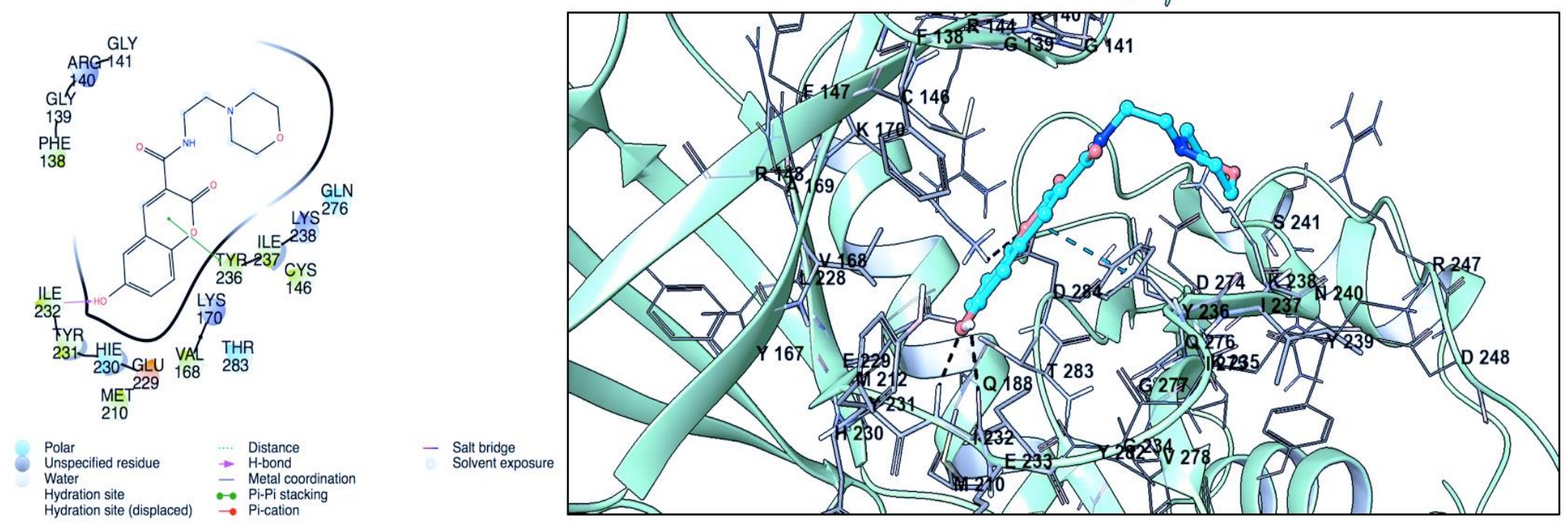

Figure 4. (A) Surface representation of top docking pose of compound 6. (B, C) 3D and 2D ligand interaction diagram of 6 at the binding pocket of the target enzyme. 


\section{eEF2K inhibitors determined in our previous reported study}

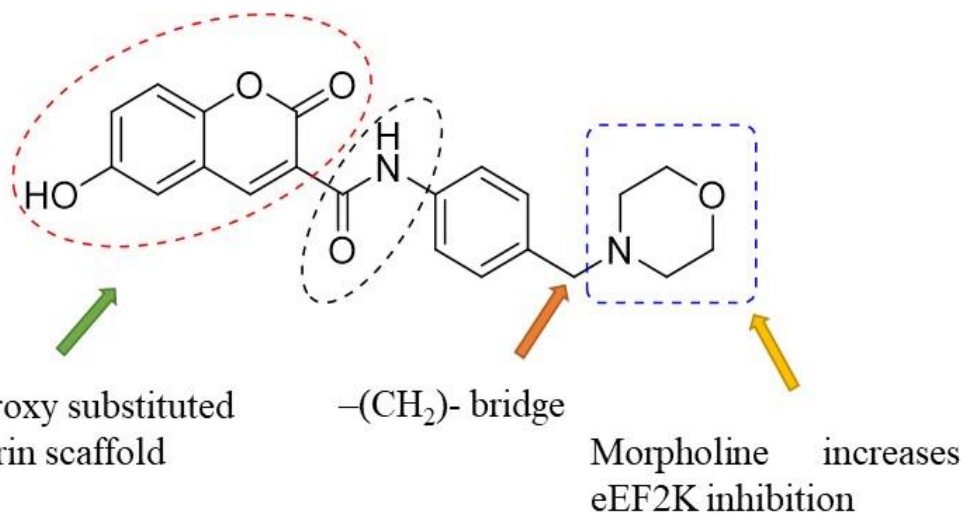

coumarin scaffold

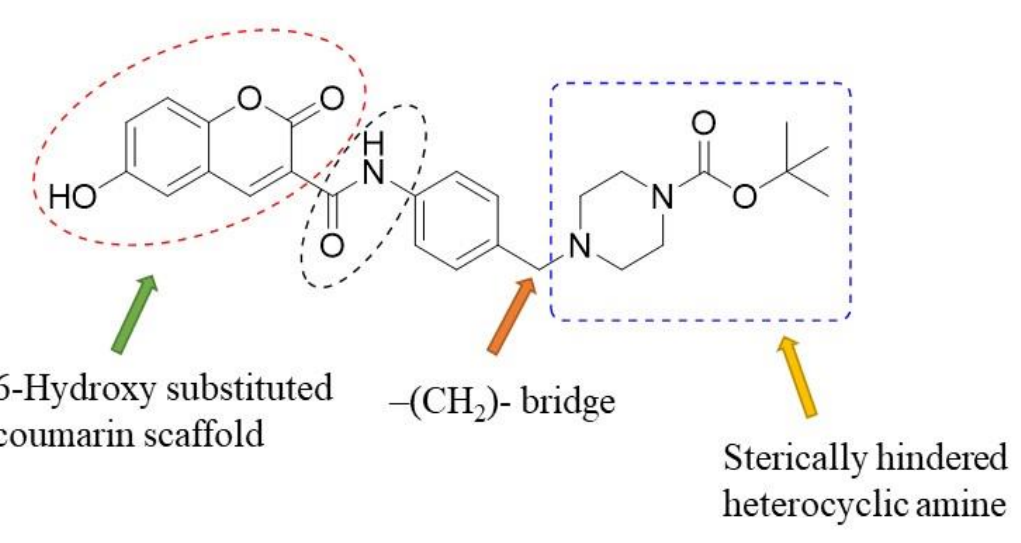

Compound $\mathbf{A 1}$ and $\mathbf{A 2}$ have significant inhibitory activity against eEF2K at 1 and $2.5 \mu \mathrm{M}$ Compound $\mathbf{A 1}$ and $\mathbf{A} 2$ are better than other eEF2K inhibitors for potency and selectivity

6-Hydroxy substituted coumarin scaffold

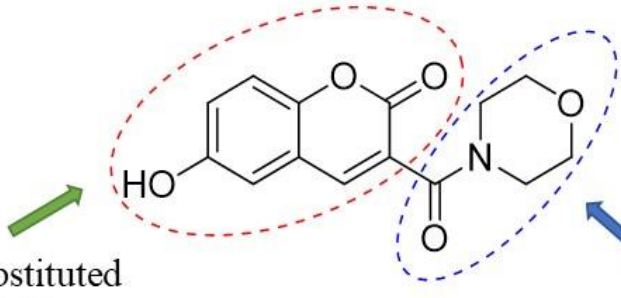

Tertiary amide including morpholine group

Compound B1

No eEF2K inhibition at 1 and $2.5 \mu \mathrm{M}$

Figure 5. 


\section{Selected two potent eEF2K inhibitors from the current study}
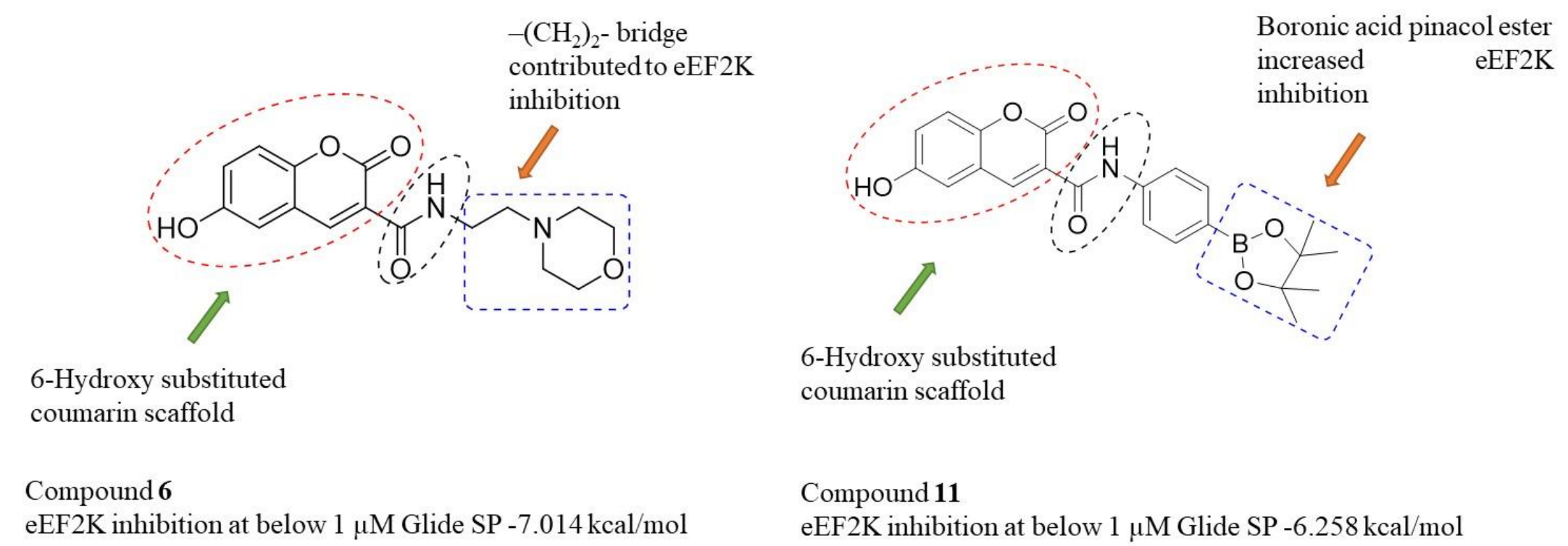

Compound 11

eEF2K inhibition at below $1 \mu \mathrm{M}$ Glide SP $-6.258 \mathrm{kcal} / \mathrm{mol}$

Figure 5 (Cont). Structure activity relationship study of developed novel eEF2K inhibitors by our group. 

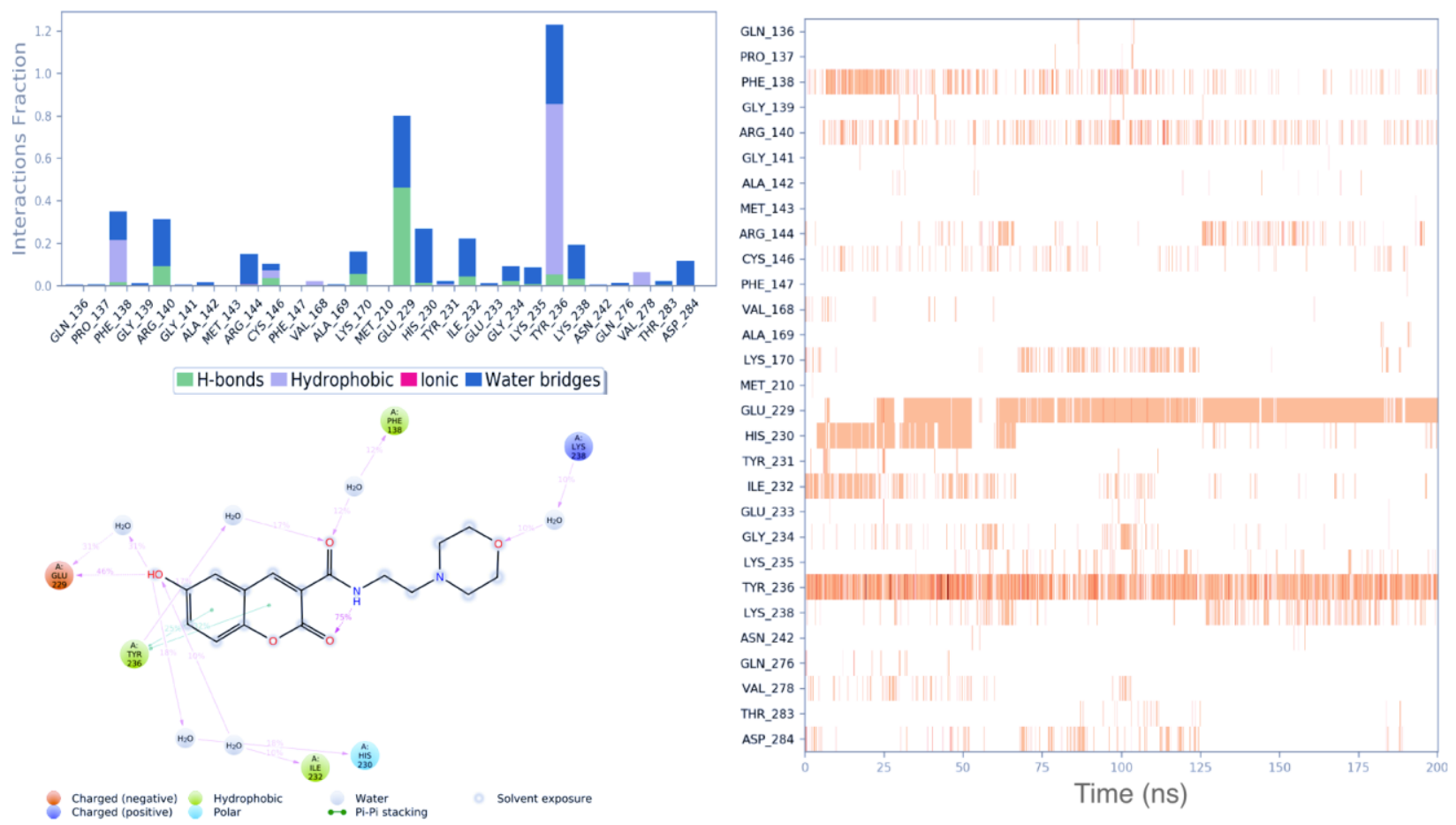

Figure 6. Ligand interaction diagrams of compound $\mathbf{6}$ at the binding pocket of the target structure throughout the MD simulations. 

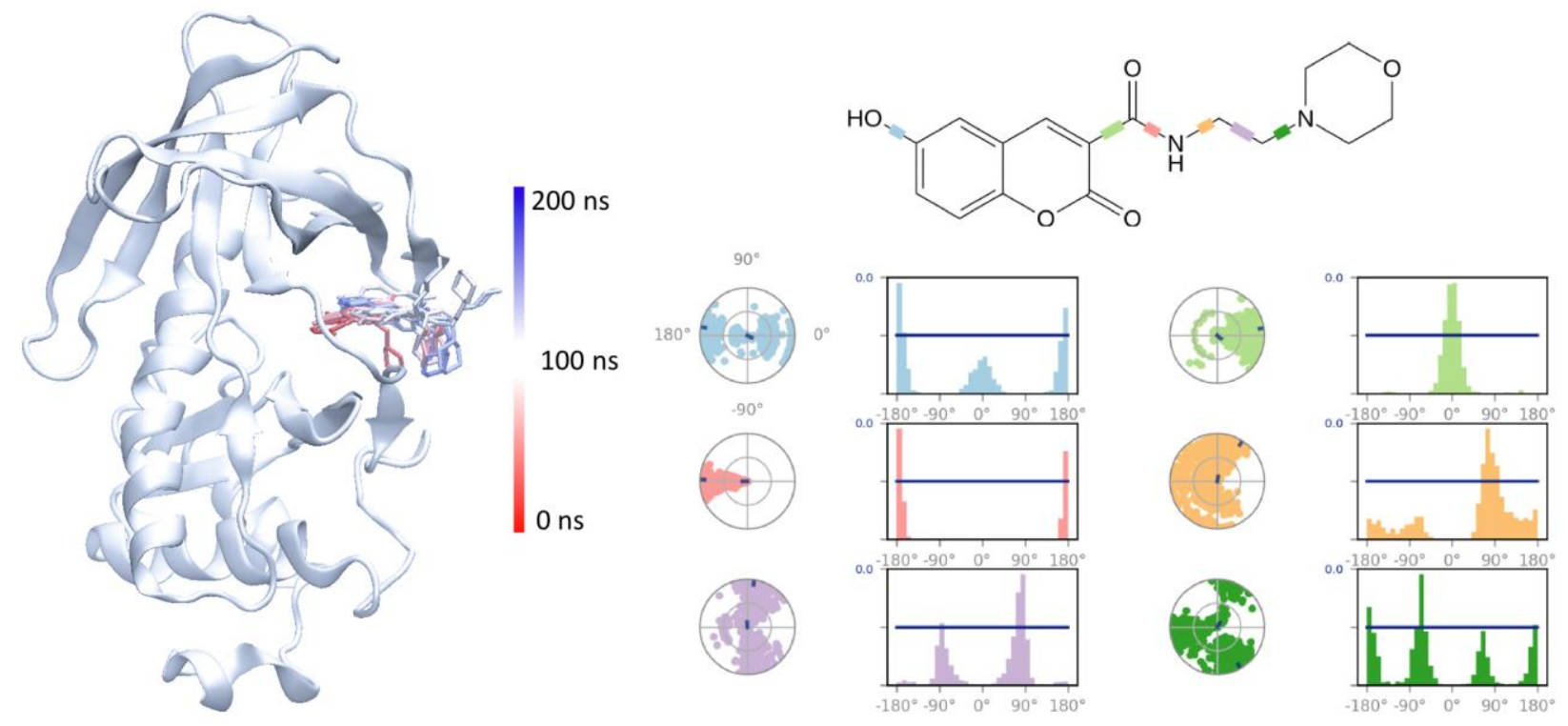

Figure 7. (left) Conformational change of the compound 6 during the MD simulations. (right) The ligand torsion plots. The conformational changes of every rotatable bond in the compound 6 during the simulation was represented with color coded bonds. Each rotatable bond dihedral angle is accompanied by a radial plot and bar plots of the same color. Radial plots describe the conformation of the torsion throughout the course of the simulation (i.e., probability density of the dihedral angles). The beginning of the simulation is in the center of the radial plot and the time evolution is plotted radially outwards. 